\title{
Mechanisms and Functional Consequences of Presynaptic Homeostatic Plasticity at Auditory Nerve Synapses
}

\author{
${ }^{\circledR}$ Xiaowen Zhuang, ${ }^{1}{ }^{\circledR}$ Nicole F. Wong, ${ }^{1}$ Wei Sun, ${ }^{2}$ and ${ }^{\circledR}$ Matthew A. Xu-Friedman ${ }^{1}$ \\ ${ }^{1}$ Department of Biological Sciences, University at Buffalo, State University of New York, Buffalo, New York 14260, and ${ }^{2}$ Center for Hearing and \\ Deafness, Department of Communicative Disorders and Sciences, University at Buffalo, State University of New York, Buffalo, New York 14214
}

Multiple forms of homeostasis influence synaptic function under diverse activity conditions. Both presynaptic and postsynaptic forms of homeostasis are important, but their relative impact on fidelity is unknown. To address this issue, we studied auditory nerve synapses onto bushy cells in the cochlear nucleus of mice of both sexes. These synapses undergo bidirectional presynaptic and postsynaptic homeostatic changes with increased and decreased acoustic stimulation. We found that both young and mature synapses exhibit similar activity-dependent changes in short-term depression. Experiments using chelators and imaging both indicated that presynaptic $\mathrm{Ca}^{2+}$ influx decreased after noise exposure, and increased after ligating the ear canal. By contrast, $\mathrm{Ca}^{2+}$ cooperativity was unaffected. Experiments using specific antagonists suggest that occlusion leads to changes in the $\mathrm{Ca}^{2+}$ channel subtypes driving neurotransmitter release. Furthermore, dynamic-clamp experiments revealed that spike fidelity primarily depended on changes in presynaptic depression, with some contribution from changes in postsynaptic intrinsic properties. These experiments indicate that presynaptic $\mathrm{Ca}^{2+}$ influx is homeostatically regulated in vivo to enhance synaptic fidelity.

Key words: auditory nerve; bushy cell; calcium imaging; endbulb of Held; release probability

\section{Significance Statement}

Homeostatic mechanisms in synapses maintain stable function in the face of different levels of activity. Both juvenile and mature auditory nerve synapses onto bushy cells modify short-term depression in different acoustic environments, which raises the question of what the underlying presynaptic mechanisms are and the relative importance of presynaptic and postsynaptic contributions to the faithful transfer of information. Changes in short-term depression under different acoustic conditions were a result of changes in presynaptic $\mathrm{Ca}^{2+}$ influx. Spike fidelity was affected by both presynaptic and postsynaptic changes after ear occlusion and was only affected by presynaptic changes after noise-rearing. These findings are important for understanding regulation of auditory synapses under normal conditions and also in disorders following noise exposure or conductive hearing loss.

\section{Introduction}

Neural circuits are subject to a wide range of activity levels, which can significantly affect synaptic function, as high activity can deplete presynaptic vesicles and reduce fidelity (Kuenzel et al., 2011). This is a particular issue at synapses with high probability of vesicle release $\left(P_{\mathrm{r}}\right)$, where depletion is fastest. There are

\footnotetext{
Received May 19, 2019; revised July 24, 2020; accepted July 28, 2020.

Author contributions: X.Z., N.F.W., and M.A.X.-F. designed research; X.Z. and N.F.W. performed research; X.Z., N.F.W., and M.A.X.-F. analyzed data; X.Z., N.F.W., and M.A.X.-F. edited the paper; X.Z. and M.A.X.-F. wrote the paper; W.S. contributed analytic tools.

The authors declare no competing financial interests.

This work was supported by National Science Foundation Award 1208131 and the National Institute on Deafness and Other Communication Disorders of the National Institutes of Health Award R01 DC015508. We thank C. Cook, S. DiCenso, V. Gellatly, T. Ngodup, M. Postolache, G. Si, H. Yang, and Y. Yang for helpful comments during the project; and F. Felmy for suggesting the train stimulation experiments.

Correspondence should be addressed to Matthew A. Xu-Friedman at mx@buffalo.edu.

https://doi.org/10.1523/JNEUROSCI.1175-19.2020

Copyright $\odot 2020$ the authors
}

homeostatic mechanisms that maintain synaptic fidelity across different levels of activity. Mammalian central synapses exhibit postsynaptic homeostasis through regulation of neurotransmitter receptors and excitability (Turrigiano et al., 1998; Song et al., 2005; Grubb and Burrone, 2010), and these mechanisms can be recruited in vivo (Hengen et al., 2013; Keck et al., 2013). There are also presynaptic forms of homeostasis that control $P_{\mathrm{r}}$ and the size of the vesicle pool (Davis, 2006; Branco et al., 2008; Delvendahl and Muller, 2019), but it is not clear how these mechanisms are recruited in vivo, or indeed what the relative importance of presynaptic versus postsynaptic homeostatic mechanisms is for spike fidelity.

A good system for gaining insights into these issues is the auditory system. Auditory nerve fibers (ANFs) show diverse firing rates depending on their sensitivity to sound level (Liberman, 1978). In addition, cochlear activity changes throughout life (Skoe et al., 2015), which could affect processing in maturity. ANFs undergo activity-dependent changes at their terminals in 
the anteroventral cochlear nucleus onto bushy cells (BCs). These synapses, called “endbulbs of Held” (Ryugo and Fekete, 1982), normally have a high $P_{\mathrm{r}}$ (Yang and Xu-Friedman, 2008, 2013). After occluding ears, $P_{\mathrm{r}}$ at endbulbs increased and BC input resistance decreased, resulting in decreased BC firing (Zhuang et al., 2017). By contrast, after noise-rearing, $P_{\mathrm{r}}$ at endbulbs and postsynaptic spike threshold both decreased, resulting in increased BC firing (Ngodup et al., 2015). This raises questions of what the underlying cellular mechanisms are, the relative importance of presynaptic versus postsynaptic changes for spike fidelity, and how mature synapses respond to changes in activity.

It is a long-standing question how $P_{\mathrm{r}}$ is set at any synapse. One possibility is through changes in $\mathrm{Ca}^{2+}$ signaling. Experimentally, manipulating $\mathrm{Ca}^{2+}$ influx affects $P_{\mathrm{r}}$ (Mintz et al., 1995; Dittman and Regehr, 1998; Cho et al., 2011; Thanawala and Regehr, 2013). Manipulation of activity in vitro triggers increases in $P_{\mathrm{r}}$ at some synapses through increased $\mathrm{Ca}^{2+}$ influx (Zhao et al., 2011; Müller and Davis, 2012; Delvendahl et al., 2019; Gratz et al., 2019). However, it is unknown whether physiological changes in activity drive a similar mechanism to regulate $\mathrm{Ca}^{2+}$ influx and $P_{\mathrm{r}}$. Another possibility is through changes in the structure of presynaptic $\mathrm{Ca}^{2+}$ domains. In immature synapses, $\mathrm{Ca}^{2+}$ channels are thought to be loosely coupled to vesicle release in so-called "microdomains," whereas in mature synapses, $\mathrm{Ca}^{2+}$ channels are tightly coupled to vesicle release in "nanodomains" (Taschenberger et al., 2002; Wang et al., 2008; Schmidt et al., 2013). Variability in domain structure has been suggested to underlie diversity of $P_{\mathrm{r}}$ and depression characteristics at auditory synapses (Fekete et al., 2019). Domain structure appears to influence the efficacy with which $\mathrm{Ca}^{2+}$ drives vesicle release, which would be reflected in the quantitative relationship between $\mathrm{Ca}^{2+}$ and release, particularly the cooperativity (Jenkinson, 1957; Dodge and Rahamimoff, 1967; Borst and Sakmann, 1996; Schneggenburger et al., 2012). It is important to understand how these factors might influence in vivo regulation of $P_{\mathrm{r}}$.

We addressed the mechanisms and consequences of synaptic changes by exposing mice to different acoustic conditions, and assessing endbulbs using electrophysiology and $\mathrm{Ca}^{2+}$ imaging in vitro. $\mathrm{Ca}^{2+}$ influx increased after ear occlusion and decreased after noise-rearing, with no changes in $\mathrm{Ca}^{2+}$ cooperativity. In addition, two-electrode dynamic-clamp experiments showed that presynaptic changes following ear occlusion and noise-rearing affected spike fidelity, while postsynaptic changes following only ear occlusion had an effect. Finally, $P_{\mathrm{r}}$ of mature endbulbs also depended on activity, indicating that this homeostatic mechanism plays a role throughout life. These experiments have important implications for understanding regulation of $P_{\mathrm{r}}$, and the impact of noise exposure or conductive hearing loss on auditory processing.

\section{Materials and Methods}

All experiments were approved by the University at Buffalo's Institutional Animal Care and Use Committee. Experimental subjects were CBA/CaJ mice (RRID:IMSR_JAX:000654) of either sex, aged from postnatal day 12 (P12) to P79.

Bilateral ear occlusion. Ears were bilaterally occluded by ligating the auditory canal at different postnatal days depending on experiments (Zhuang et al., 2017). Mice were anesthetized with $200 \mathrm{mg} / \mathrm{kg}$ ketamine plus $10 \mathrm{mg} / \mathrm{kg}$ xylazine. An incision was made beside the pinna, and a portion of the ear canal was exposed and ligated with surgical silk (Harvard Apparatus). The incision was closed using suturing and Vetbond. Mice were restored to their home cages until brain-slice electrophysiology recordings.
Noise-rearing. Mice were exposed to broadband noise using a white noise generator (ACO Pacific 3025), driving a Fostex speaker (FT28D) mounted above the animal cage (Ngodup et al., 2015). Noise level was measured over a frequency range of $1-20 \mathrm{kHz}$ at $1 / 3$ octave intervals using a Larson-Davis sound level meter (824). Intensity depended on the location within the cage and orientation of the microphone, with maximum intensity ranging from $76-86 \mathrm{~dB}$ SPL, and minimum from 64-84 dB SPL. Normal conditions (with the noise speaker off) were 21$38 \mathrm{~dB}$ SPL in the university animal facility.

Brain-slice electrophysiology. Parasagittal slices of anteroventral cochlear nucleus were cut from the auditory brainstem of mice as described previously (Yang and Xu-Friedman, 2008, 2015). Briefly, slices $(142 \mu \mathrm{m})$ were cut in an ice-cold sucrose-based solution containing the following (in mM): $76 \mathrm{NaCl}, 75$ sucrose, $25 \mathrm{NaHCO}_{3}, 25$ glucose, 2.5 $\mathrm{KCl}, 1.25 \mathrm{NaH}_{2} \mathrm{PO}_{4}, 7 \mathrm{MgCl}_{2}, 0.5 \mathrm{CaCl}_{2}$. Then slices were transferred and incubated at $30^{\circ} \mathrm{C}$ for $20 \mathrm{~min}$ in standard recording solution containing the following (in $\mathrm{mM}$ ): $125 \mathrm{NaCl}, 26 \mathrm{NaHCO}_{3}, 2.5 \mathrm{KCl}, 1.25$ $\mathrm{NaH}_{2} \mathrm{PO}_{4}, 20$ glucose, $1.5 \mathrm{CaCl}_{2}, 1 \mathrm{MgCl}_{2}, 4 \mathrm{Na}$-L-lactate, $2 \mathrm{Na}$-pyruvate, $0.4 \mathrm{Na}$-L-ascorbate, bubbled with $95 \% \mathrm{O}_{2} / 5 \% \mathrm{CO}_{2}$. Slices from animals older than P35 were cut in standard recording solution and incubated in NMDG-HEPES recovery solution (in $\mathrm{mM}$ as follows: 93 NMDG, 2.5 $\mathrm{KCl}, 1.2 \mathrm{NaH}_{2} \mathrm{PO}_{4}, 30 \mathrm{NaHCO}_{3}, 20$ HEPES, 25 glucose, $5 \mathrm{Na}$-L-ascorbate, $3 \mathrm{Na}$-pyruvate, $10 \mathrm{MgCl}_{2}, 0.5 \mathrm{CaCl}_{2}$; osmolarity: $\sim 310 \mathrm{mOsm}$ ) for $15 \mathrm{~min}$ before transferring to standard recording solution. Strychnine $(5 \mu \mathrm{M})$ was present during all recordings to block glycine receptors. Strychnine is reported to affect input resistance at $10 \mu \mathrm{M}$ (Franken et al., 2015). We did not verify this effect in BCs at $5 \mu \mathrm{M}$; but since our recordings were all conducted under the same conditions, between-condition comparisons appear valid. Kynurenate $(1 \mathrm{mM})$ was included for EPSC measurements in Figures 6 and 8 to avoid receptor saturation. $\mathrm{Ca}^{2+}$ channel antagonists $\omega$-conotoxin GVIA $(0.5 \mu \mathrm{M})$ and $\omega$-agatoxin IVA $(0.2 \mu \mathrm{M})$ were used in the experiments of Figure 8 (Sigma, Alomone Labs). In these experiments, ACSF was recirculated to conserve antagonist. The efficacy of the $\mathrm{Ca}^{2+}$ channel antagonists at these concentrations was verified in pilot experiments by doubling the concentration, which did not block EPSCs further (data not shown).

BCs were patched under an Olympus BX51WI microscope with a Multiclamp 700B (Molecular Devices) controlled by a National Instruments PCI-6221 or Instrutech ITC-18, driven by custom-written software (mafPC) running in Igor (WaveMetrics, RRID:SCR_000325). The bath was perfused at 3-4 $\mathrm{ml} / \mathrm{min}$ using a pump (403U/VM2; Watson-Marlow), with recording solution running through an inline heater to maintain the temperature at $33^{\circ} \mathrm{C}(\mathrm{SH}-27 \mathrm{~B}$ with TC-324B controller; Warner Instruments).

Pipettes were pulled from borosilicate glass (OD: $1.5 \mathrm{~mm}$, ID: 0.86 $\mathrm{mm}$; Sutter Instruments) to a resistance of 1.5-2.5 $\mathrm{M} \Omega$ and were filled with internal solution for voltage clamp containing (in $\mathrm{mM}$ ): $35 \mathrm{CsF}$, $100 \mathrm{CsCl}, 10$ EGTA, 10 HEPES, and 1 QX-314. BCs were held at $-70 \mathrm{mV}$, with access resistance 5-15 $\mathrm{m} \Omega$ compensated to $70 \%$. Cells were identified by EPSCs having rapid decay kinetics $(\tau<0.2 \mathrm{~ms})$ and half-width $\leq 0.5 \mathrm{~ms}$ (Chanda and Xu-Friedman, 2010a). A single ANF input onto a $\mathrm{BC}$ was isolated and stimulated using a glass microelectrode placed 30-50 $\mu \mathrm{m}$ away from the soma with currents of 10-25 $\mu \mathrm{A}$ through a stimulus isolator (WPI A360).

The two classes of BCs, spherical and globular, are not as physiologically and regionally distinct in mice compared with other species (Lauer et al., 2013). Auditory nerve synapses onto globular BCs of cats are called "modified endbulbs"; but in mice this distinction is rarely made, so all recordings were pooled together.

Round window injection of $\mathrm{Ca}^{2+}$ indicator. Mice were anesthetized with $200 \mathrm{mg} / \mathrm{kg}$ ketamine and $10 \mathrm{mg} / \mathrm{kg}$ xylazine, then positioned right ear down on a $37^{\circ} \mathrm{C}$ warming pad to maintain body temperature. The skin posterior to the ear was depilated with Nair, and sterilized with $70 \%$ ethanol and betadine. Marcaine $(1 \mu \mathrm{l})$ was injected underneath the skin (Chanda et al., 2011). Next, a small skin incision was made and muscle tissue was dissected with forceps to expose the otic bulla. A small hole was made in the bulla to visualize the round window membrane without disrupting the tympanic membrane and malleus. A $5 \mu \mathrm{l}$ syringe (Hamilton, HAM7634-01, 34-gauge needle) was loaded with $0.5 \mu \mathrm{l}$ of 
$10 \%$, 3000-MW-dextran-conjugated calcium green-1 and $1 \mu \mathrm{l}$ of $10 \%$, 3000-MW-dextran-conjugated Texas red (Invitrogen) to visualize the endbulbs. The needle was positioned in the round window niche, and the dye was injected into the cochlea. The skin incision was closed using sutures or Vetbond, and 12-24 h was allowed for diffusion of the dyes before imaging.

To assess hearing thresholds after cochlear injection, auditory brainstem responses (ABRs) were recorded $12-24 \mathrm{~h}$ after cochlear dye injection. Mice were anesthetized with $200 \mathrm{mg} / \mathrm{kg}$ ketamine plus $10 \mathrm{mg} / \mathrm{kg}$ xylazine. ABRs were recorded in a soundproof room with an auditoryevoked response averaging system controlled by TDT software (BioSig, RRID:SCR_006495) (Sun et al., 2009). Animals were inserted with vertex electrode, an electrode behind the pinna ipsilateral to the stimulated ear, and a ground electrode contralateral to the stimulated ear. Clicks (100 $\mu \mathrm{s})$ were presented through a speaker placed into the ear canal. ABR threshold was obtained for each animal by reducing the stimulus intensity in $10 \mathrm{~dB}$ steps and then $5 \mathrm{~dB}$ steps to identify the lowest intensity that elicited a response.

$\mathrm{Ca}^{2+}$ imaging. Labeled presynaptic endbulbs were visualized using a $60 \times$ water-immersion objective under a $\mathrm{pE}-300^{\text {ultra }}$ LED light source (CoolLED) with excitation/dichronic/emission filters of 560DF55/595/ 645DF75 (for Texas red) or 480DF40/505/535DF50 (for calcium green). Fluorescence was recorded with a photodiode (S1226, Hamamatsu) with $5 \mathrm{G} \Omega$ feedback resistor (time constant $1.6 \mathrm{~ms}$ ). All fluorescence increases from endbulbs were confirmed with a camera (Sensicam QE, Cooke) controlled by SIDX drivers running in Igor. Photodiode measurements averaged over the FOV, which was limited as much as possible using a diaphragm, and were normalized to baseline fluorescence to yield the $\Delta F / F$, without background subtraction.

Dynamic clamp. In order to mimic presynaptic conductances, we first collected trains of EPSCs at $100 \mathrm{~Hz}$ in voltage clamp from endbulbs exposed to three acoustic conditions, and then converted them into conductances. The dynamic clamp was implemented as a master-slave setup as described by Yang et al. (2015). Each BC was patched with two 3-4 $\mathrm{M} \Omega$ pipettes containing current-clamp solution (in $\mathrm{mM}$ as follows: 130 $\mathrm{KMeSO}_{3}, 10 \mathrm{NaCl}, 2 \mathrm{MgCl}_{2}, 0.16 \mathrm{CaCl}_{2}, 0.5$ EGTA, 10 HEPES, 4 $\mathrm{Na}_{2}$ ATP, $0.4 \mathrm{NaGTP}$, and 14 Tris-CrPhos). One electrode measured cell voltage and the other electrode passed current. The presynaptic conductances were delivered by the master computer to the slave computer and applied to the BCs by the dynamic clamp. The amplitude of the first synaptic conductance was set to 5 times the BC's conductance threshold, such that the average dynamic-clamp conductance amplitude was near the average measured EPSC amplitude across all three conditions (Yang and Xu-Friedman, 2010). BC spikes were identified in the dynamicclamp recordings after subtracting the predicted effects on the membrane potential of the applied conductances for a simple RC model cell.

Experimental design and statistical analysis. Average results are reported throughout as mean \pm SEM. Animals of both sexes were used. The number of cells per group is indicated in the text associated with each experiment. For most comparisons, between 10 and 20 cells were needed because of high variability in paired pulse ratios (PPRs) and EPSC amplitudes. The statistical significance level was set at $p<0.05$, and exact values are shown in the text. Comparisons between two groups were made using unpaired Student's $t$ tests. For comparisons of three or more groups, ANOVA tests were used with Tukey's post hoc test.

\section{Results}

\section{$P_{\mathrm{r}}$ at mature synapses}

We first addressed the functional importance of synaptic changes at mature synapses by exposing mice to different acoustic conditions. We exposed one group of mice to constant, low-intensity, broadband noise (see Materials and Methods). Previous work has shown that hair cell damage and synaptopathy are minimal at this intensity (Ngodup et al., 2015). We occluded the ears in another group of mice by ligating the ear canal, which increases hearing threshold by $50 \mathrm{~dB}$ SPL (Zhuang et al., 2017). The efficacy of ligation is reduced at low frequencies (Popescu and
Polley, 2010), so the effects on activity could vary in different parts of the cochlea, which may introduce additional variance into our results. We assessed endbulb $P_{\mathrm{r}}$ by quantifying the level of synaptic depression in whole-cell voltage-clamp recordings from acute slices of the cochlear nucleus. We stimulated pairs of EPSCs at a $3 \mathrm{~ms}$ interval, and calculated the PPR (PPR $=\mathrm{EPSC}_{2} /$ EPSC $_{1}$ ). These recordings were made in the absence of a low-affinity antagonist, so PPR is influenced by receptor desensitization and saturation (Chanda and Xu-Friedman, 2010a). Under these conditions, PPR is an indirect but reliable measure of $P_{\mathrm{r}}$. A representative recording from a P62 mouse that was reared in normal sound conditions shows typical strong depression (Fig. 1A,B; "Ctrl"). We ligated ear canals at either P14 (Occ, $\left(\mathrm{Occ}_{\mathrm{old}}\right)$ and recorded after P57, by which time both groups showed more depression (Fig. $1 B$ ), and the decrease in PPR was significant (Fig. 1C; Ctrl: $0.51 \pm 0.03,8$ cells; Occ young $_{\text {: }} 0.36 \pm$ $0.03,6$ cells, $p=0.02$; Occ old $_{1}: 0.38 \pm 0.04,12$ cells, $p=0.04$ ), indicating that $P_{\mathrm{r}}$ increased after ear occlusion.

Similarly, we exposed mice to noise beginning at either P12 $\left(\mathrm{Nr}_{\text {young }}\right)$ or P51 $\left(\mathrm{Nr}_{\text {old }}\right)$ and recorded after P57. Both groups showed less depression (Fig. 1B), and the increase in PPR was significant (Fig. $1 C ; \mathrm{Nr}_{\text {young: }} 0.64 \pm 0.04,9$ cells, $p=0.04 ; \mathrm{Nr}_{\text {old }}$ : $0.66 \pm 0.03,10$ cells, $p=0.004)$, indicating that $P_{\mathrm{r}}$ decreased after noise-rearing. To test whether these changes recover, we exposed some mice to noise until $\sim \mathrm{P} 51$, then returned to normal sound conditions before assessing PPR after P64. The example in Figure $1 B(\operatorname{Rec})$ shows similar PPR to control, and average PPR was not significantly different (Fig. $1 C$; Rec: $0.51 \pm 0.02,7$ cells, $p=0.9$ ). We did not attempt recovery experiments after longterm occlusion because of concerns whether the ears returned to normal function (Qi et al., 2019). Thus, $P_{\mathrm{r}}$ depends on activity for both immature and mature endbulbs, and we found no evidence of a critical period. This suggests that endbulbs adapt to sensory experience throughout life.

In addition, we confirmed that other properties of the EPSC showed little change, similar to our previous findings in younger endbulbs. The population average of the amplitude of the first EPSC (EPSC $)_{1}$ was similar across all treatment groups (Fig. $1 D$; Ctrl: $8.22 \pm 1.49 \mathrm{nA}$; Occ young $_{\text {y }} 10.02 \pm 1.95 \mathrm{nA}$; Occ old $_{10} 10.75 \pm$ 1.26; $\mathrm{Nr}_{\text {young: }} 9.40 \pm 1.41 \mathrm{nA} ; \mathrm{Nr}_{\text {old }}: 7.00 \pm 0.50 \mathrm{nA}$; Rec: $9.39 \pm$ $2.18 \mathrm{nA} ; p>0.05$ for all comparisons to control). In addition, the decay tau of $\mathrm{EPSC}_{1}$ showed no significant changes (Fig. $1 E$; Ctrl: $181 \pm 9 \mu \mathrm{s} ;$ Occ $_{\text {young }}: 190 \pm 18 \mu \mathrm{s} ;$ Occ $_{\text {old }}: 188 \pm 4 \mu \mathrm{s} ; \mathrm{Nr}_{\text {young }}$ : $192 \pm 7 \mu \mathrm{s} ; \mathrm{Nr}_{\text {old }}: 195 \pm 10 \mu \mathrm{s} ;$ Rec: $197 \pm 14 \mu \mathrm{s} ; p>0.32$ for all comparisons to control).

\section{$\mathrm{Ca}^{2+}$ signaling}

We wanted to determine the cellular mechanisms underlying the activity-dependent regulation of $P_{\mathrm{r}}$. Presynaptic $\mathrm{Ca}^{2+}$ signaling is a primary regulator of neurotransmitter release (Mintz et al., 1995; Augustine, 2001; Sudhof, 2012), so we investigated its contribution by applying $\mathrm{Ca}^{2+}$ chelators. BAPTA-AM is a fast $\mathrm{Ca}^{2+}$ chelator; and when it is applied to slices, it is taken up by presynaptic endbulbs (Tsien, 1980). The postsynaptic BC is unaffected because the patch pipette sets its intracellular composition. While young and mature endbulbs are subject to similar changes in $P_{\mathrm{r}}$, it is easier technically to address the underlying mechanisms in younger endbulbs. We therefore either exposed mice to noise at P12 or occluded the ear canal at P14, and performed voltage-clamp recordings after P21 (Fig. $2 A$ ).

We measured EPSCs from occluded, noise-reared, and agematched control endbulbs before and after applying $100 \mu \mathrm{M}$ BAPTA-AM for $5 \mathrm{~min}$ (Fig. 2B). Application time was held 
A

\begin{tabular}{|c|c|c|c|}
\hline & & $12 / 14$ & $\sim$ P51 \\
\hline Occ young & Norm & Occ & \\
\hline $\mathrm{Occ}_{\text {old }}$ & Norm & & IOcc \\
\hline Ctrl & Norm & & \\
\hline $\mathrm{Nr}_{\text {young }}$ & Norm & $\mathrm{Nr}$ & \\
\hline $\mathrm{Nr}_{\text {old }}$ & Norm & & $\mathrm{INr}$ \\
\hline $\operatorname{Rec}$ & Norm & $\mathrm{Nr}$ & Norr \\
\hline
\end{tabular}

B

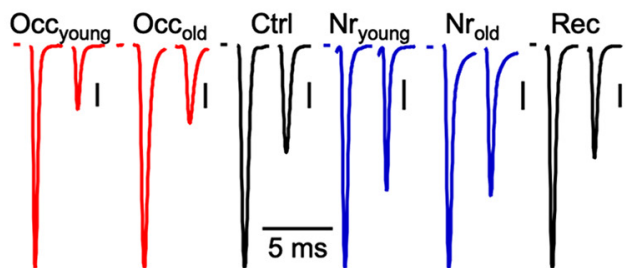

C

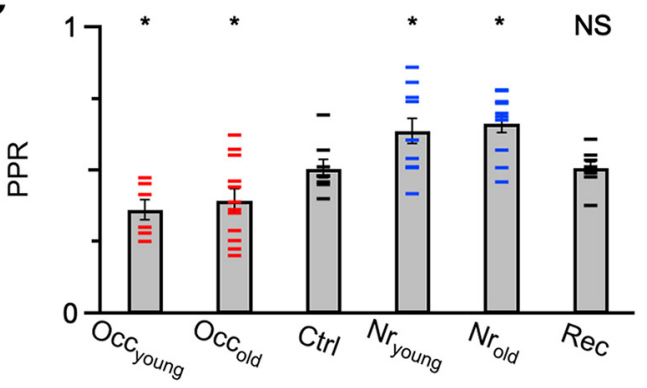

D

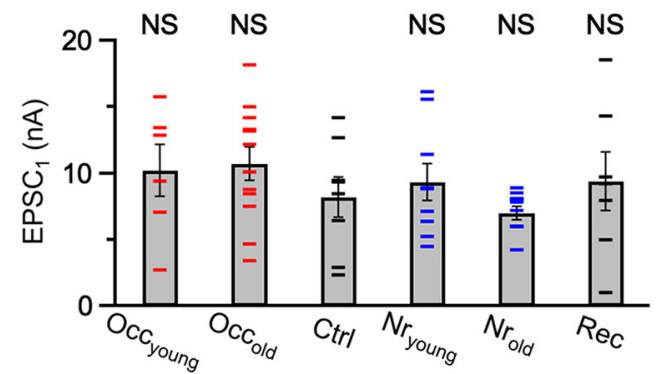

E

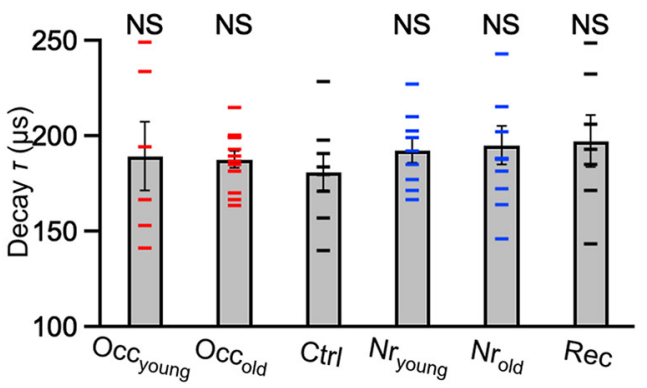

Figure 1. Acoustically-driven changes in mature synapses. $\boldsymbol{A}$, Experimental timeline for acoustic manipulations. All cells were recorded after P57. Ctrl mice were raised under normal (Norm) sound conditions. Occyoung mice were occluded at P14 until recordings. Occold mice were occluded at P51 until recordings. $\mathrm{Nr}_{\text {young }}$ mice were noise-reared at P12 until recordings. $\mathrm{Nr}_{\text {old }}$ mice were noise-reared at P51 until recordings. Rec (recovery) mice were noisereared between P12 and P51, then held in normal sound conditions until recordings. $\boldsymbol{B}$, Representative EPSCS from mice raised in the sound conditions in $A$. A single presynaptic ANF was isolated and stimulated in pairs with a $3 \mathrm{~ms}$ interval. Vertical bars $=1 \mathrm{nA}$. C $-\boldsymbol{E}$, PPR $(\boldsymbol{C})$, EPSC $C_{1}$ amplitude $(\boldsymbol{D})$, and decay $\tau(\boldsymbol{E})$ for different treatment groups in $\boldsymbol{A}$. Error bars indicate mean \pm SEM. Horizontal markers represent individual experiments (7-12 cells each condition). ${ }^{*} p<0.05$, NS $=$ not significant $(p>0.05)$.
A
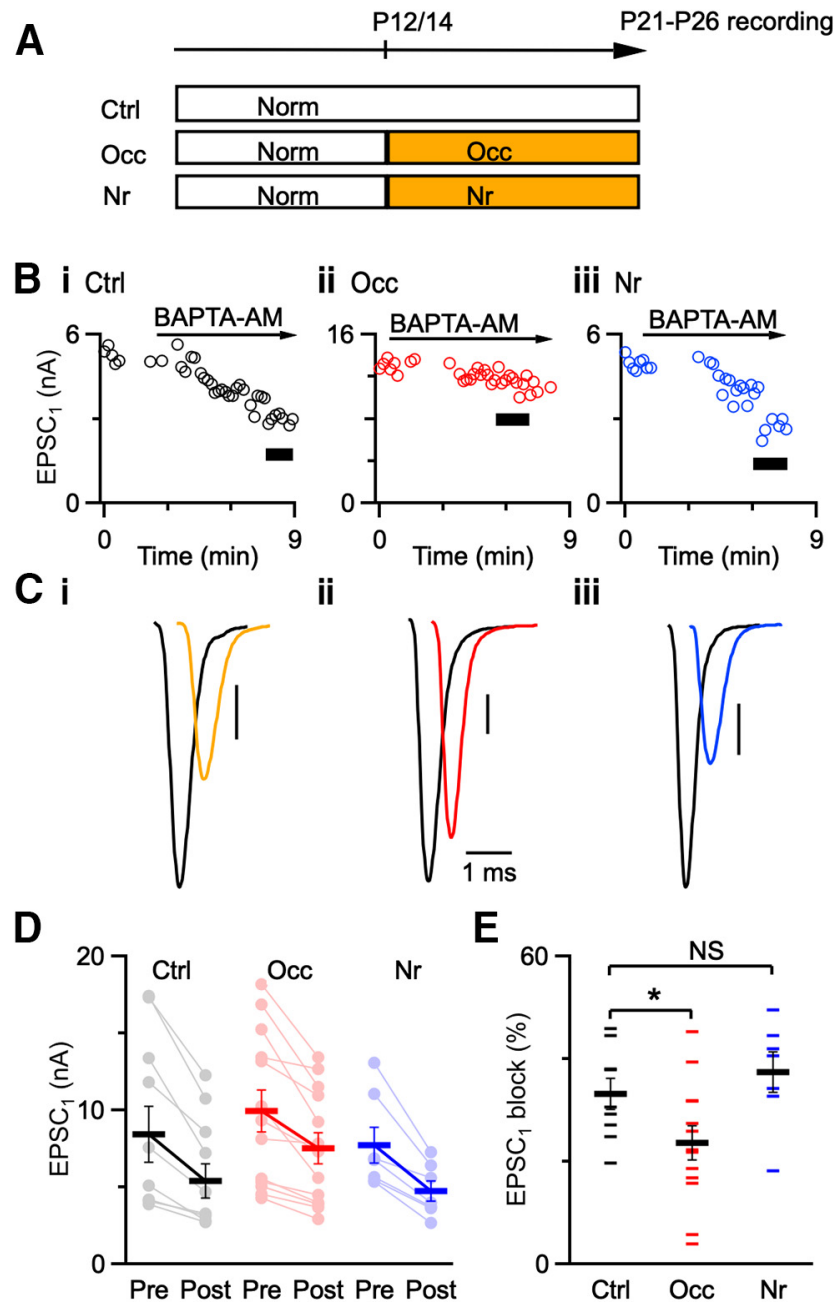

Figure 2. Effects of BAPTA-AM. A, Experimental timeline for acoustic manipulations. Ctrl mice were raised under normal sound conditions until recordings. Occ mice were occluded at P14, and Nr mice were noise-reared at P12 until recording between P21 and P26. $\boldsymbol{B}$, Representative traces showing effects of BAPTA-AM on EPSC ${ }_{1}$ amplitude from control (Bi), occluded (Bii), and noise-reared (Biii) mice. Black bars represent EPSCs after 5 min application of $100 \mu \mathrm{M}$ BAPTA-AM that were used for analysis. C, Average EPSC ${ }_{1}$ before (black traces) and after (color traces) 5 min application of BAPTA-AM. Cells are from P21 to P26 mice. Vertical bars $=1 \mathrm{nA}$. $D$, Individual $E P S C_{1}$ amplitude of all recordings before and after bath application of BAPTA-AM under different acoustic conditions (7-13 cells each condition). $\boldsymbol{E}$, Percent block of EPSC $C_{1}$ after applying BAPTA-AM for the three acoustic conditions. BAPTAAM is less effective at blocking EPSC ${ }_{1}$ after occlusion compared with controls. Small horizontal markers represent individual recordings. Large horizontal markers represent mean \pm SEM. ${ }^{*} p<0.05$.

constant to ensure that equal amounts of BAPTA were loaded in each experiment. BAPTA blocked EPSCs from control and noise-reared endbulbs with high efficacy, but not occluded endbulbs (Fig. 2C; black represents before BAPTA-AM wash-in, and color represents after BAPTA-AM wash-in, Fig. 2D; Ctrl before: $8.43 \pm 1.82 \mathrm{nA}$, after: $5.41 \pm 1.09 \mathrm{nA}, 9$ cells; Occ before: $9.95 \pm$ $1.38 \mathrm{nA}$, after: $7.51 \pm 1.03 \mathrm{nA}, 13$ cells; $\mathrm{Nr}$ before: $7.74 \pm$ $1.16 \mathrm{nA}$, after: $4.77 \pm 0.33 \mathrm{nA}, 7$ cells). On average, the percent block of $\mathrm{EPSC}_{1}$ was similar for control and noise-reared endbulbs, but BAPTA had significantly less effect on $\mathrm{EPSC}_{1}$ from occluded endbulbs (Fig. $2 E$; Ctrl: $33 \pm 3 \%$, 9 cells; $\mathrm{Nr}$ : $37 \pm 4 \%$, 7 cells; $p=0.4$; Occ: $24 \pm 3 \%, 13$ cells; $p=0.04$ ).

We next tested the blocking effects of a slower $\mathrm{Ca}^{2+}$ chelator, EGTA, on synaptic transmission. EGTA at endbulbs reduces residual- $\mathrm{Ca}^{2+}$-dependent recovery (Yang and Xu-Friedman, 
2008). We used this to verify wash-in of EGTA by stimulating ANFs with a 5 pulse, $100 \mathrm{~Hz}$ train followed by a test pulse at a $100 \mathrm{~ms}$ delay (EPSC test Fig. 3A). After bath application of $20 \mu \mathrm{M}$ EGTA-AM for 5 min, the amplitude of EPSC $C_{\text {test }}$ significantly decreased in both control and occluded groups (Fig. 3B), indicating that there was effective wash-in of EGTA. EPSC test did not decrease significantly after noise-rearing (Fig. $3 B$ ), suggesting that noise-rearing may also affect $\mathrm{Ca}^{2+}$-dependent recovery mechanisms. EPSC $_{1}$ was little affected by EGTA in control and occluded endbulbs but was blocked in noise-reared endbulbs with high efficacy (Fig. 3C,D). We saw similar effects on average for both $\mathrm{EPSC}_{1}$ (Fig. $3 E$; Ctrl before: $10.36 \pm 2.73 \mathrm{nA}$, after: $9.41 \pm 2.36 \mathrm{nA}, 6$ cells; Occ before: $11.89 \pm 2.67 \mathrm{nA}$, after: $11.18 \pm$ $2.71 \mathrm{nA}, 8$ cells; $\mathrm{Nr}$ before: $6.59 \pm 1.11 \mathrm{nA}$, after: $5.30 \pm 0.91 \mathrm{nA}, 7$ cells) and percent block by EGTA-AM (Fig. 3F; Ctrl: $8 \pm 3 \%, 6$ cells; Occ: $7 \pm 3 \%, 8$ cells; $p=0.9 ; \mathrm{Nr}: 19 \pm 5 \%, 7$ cells; $p=0.04$ ).

These results indicate that acoustic experience influences presynaptic $\mathrm{Ca}^{2+}$ signaling at endbulbs. The results with BAPTA$\mathrm{AM}$ are consistent with increased $\mathrm{Ca}^{2+}$ influx or tighter coupling between the $\mathrm{Ca}^{2+}$ sensor and $\mathrm{Ca}^{2+}$ channels after occlusion. The results with EGTA-AM are consistent with decreased $\mathrm{Ca}^{2+}$ influx or looser coupling between the $\mathrm{Ca}^{2+}$ sensor and $\mathrm{Ca}^{2+}$ channels at endbulbs after noise-rearing. Because the effects of exogenous chelators are influenced by both changes in influx and coupling (Nakamura et al., 2018), additional tests are needed to distinguish these possibilities.

\section{$\mathrm{Ca}^{2+}$ imaging}

EGTA and BAPTA experiments suggested that endbulbs regulate the level of synaptic depression by adjusting presynaptic $\mathrm{Ca}^{2+}$ signaling under different sound conditions. In order to test whether this resulted from changes in $\mathrm{Ca}^{2+}$ influx, we used $\mathrm{Ca}^{2+}$ imaging. We loaded ANFs with dextran-conjugated calcium green-1, which is a high-affinity $\mathrm{Ca}^{2+}$-sensitive indicator (Kreitzer et al., 2000), by coinjecting it with Texas red into the cochlea and allowing overnight diffusion (Chanda et al., 2011). This method causes some damage to the cochlea and elevated hearing threshold (Fig. 4A,B). However, we minimized the time between injection and imaging to preserve the consequences of different acoustic environments for synaptic depression (Fig. 4C; Ctrl: $0.54 \pm 0.05,9$ cells; Ctrl Inj: 0.42 $\pm 0.04,11$ cells; $p=0.06$; Occ: $0.34 \pm 0.02,32$ cells; Occ Inj: $0.32 \pm 0.03,16$ cells; $p=0.7$; Nr: $0.70 \pm 0.04,12$ cells; Nr Inj: $0.70 \pm 0.07,8$ cells; $p=0.9$ ).

Endbulbs were recognized by their morphology in Texas red fluorescence, as well as by being adjacent to a healthy $\mathrm{BC}$ (Chanda et al., 2011) (Fig. 4Di,Dii). $\mathrm{Ca}^{2+}$ signals were confirmed as originating from endbulbs by observing localized increases in fluorescence following stimulation using a camera (Fig. $4 D i i i-D v$ ). Typically, only restricted parts of the endbulb increased fluorescence on stimulation (Fig. 4Diii$D v$, yellow box), which are presumably the areas corresponding to active release sites.

To acquire higher temporal resolution of $\mathrm{Ca}^{2+}$ transients, we switched to photodiode measurements. Round window injections yield endbulbs with different indicator concentrations, which provides important experimental advantages. For synapses with high concentrations of calcium green-1, $\mathrm{Ca}^{2+}$ entering after one stimulus will occupy a small fraction of the available indicator, so $\mathrm{Ca}^{2+}$ influx on subsequent stimuli would produce similar fluorescence changes. Thus, overloaded endbulbs provide a linear measure of $\mathrm{Ca}^{2+}$ levels. For synapses with low concentrations of calcium green-1, $\mathrm{Ca}^{2+}$ levels that approach the dissociation constant $\left(K_{\mathrm{D}}\right)$ of calcium green-1 will show saturation. In other
A

B
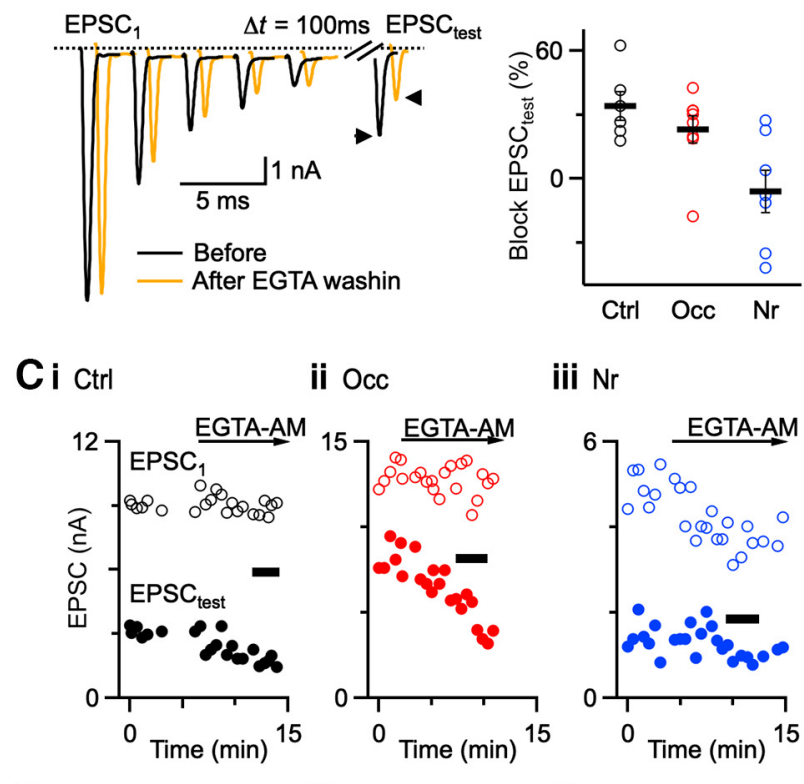

Di

ii Occ

iii $\mathrm{Nr}$

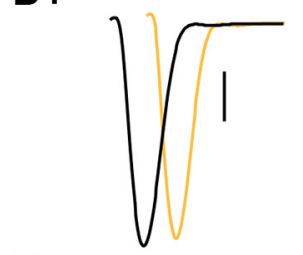

ii
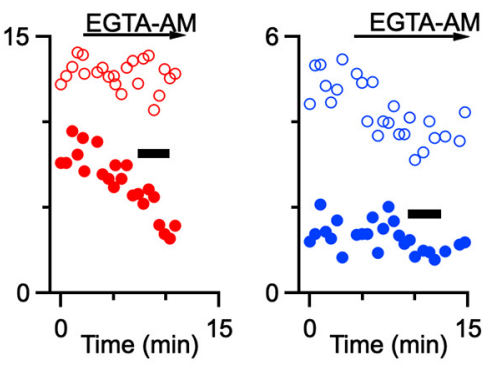

E

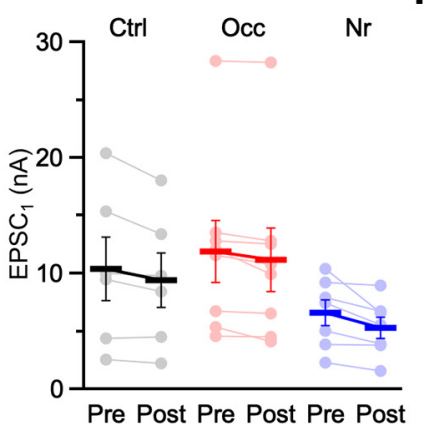

$\mathbf{F}$ iii
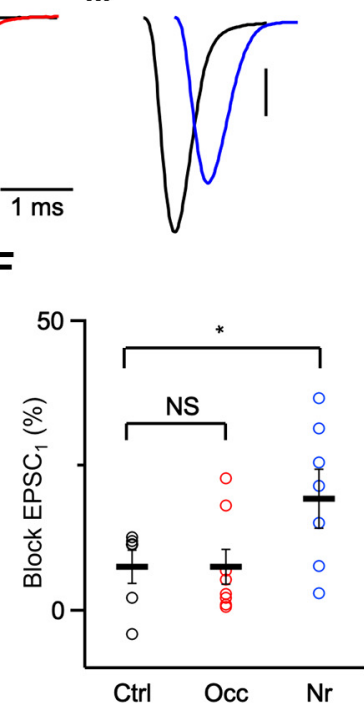

Figure 3. Effects of EGTA-AM. A, Representative traces from a control mouse showing effects of $20 \mu \mathrm{M}$ EGTA-AM on EPSCS. There was little effect on EPSC amplitude during 5pulse, 100-Hz trains, but significant reduction of a test pulse (EPSC $C_{\text {test }}$ ) after $100 \mathrm{~ms}$ recovery.

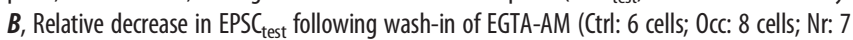
cells). EPSC $C_{\text {test }}$ decreased significantly in both control and occluded groups, but not after noise-rearing. $C$, Time course of EGTA-AM wash-in for EPSC $C_{1}$ and EPSC $C_{\text {test. }}$. Black bars represent traces averaged in $\boldsymbol{D}$. D, Average traces before (black) and after (color) EGTA-AM application. All traces are average of 5-10 trials. $\boldsymbol{E}$, Individual EPSC amplitude of all recordings before and after application of EGTA-AM under different acoustic conditions (Ctrl: 6 cells; 0 cc: 8 cells; Nr: 7 cells). $\boldsymbol{F}$, Percent block of EPSC after applying EGTA-AM in control, occluded, and noise-reared mice. EGTA-AM blocks EPSC ${ }_{1}$ more effectively in noise-reared mice than in control and occluded mice $(p=0.04) .{ }^{*} p<0.05$, NS $=$ not significant $(p>0.05)$.

words, $\mathrm{Ca}^{2+}$ entering after one stimulus will occupy a large fraction of the available indicator, which reduces fluorescence changes despite identical $\mathrm{Ca}^{2+}$ influx on subsequent stimuli (Sabatini and Regehr, 1995). The degree of saturation would be greater when $\mathrm{Ca}^{2+}$ influx is higher and smaller when $\mathrm{Ca}^{2+}$ influx is lower. Thus, saturation provides insight into the magnitude of $\mathrm{Ca}^{2+}$ influx. These two situations can be distinguished by the decay of $\mathrm{Ca}^{2+}$ transients, which is slower at higher indicator concentration (Regehr and Atluri, 1995; Helmchen et al., 1996). 
A

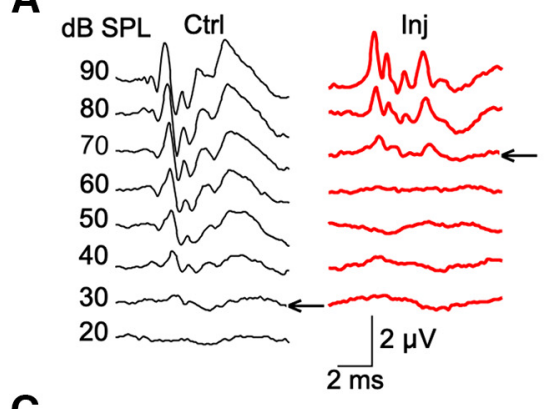

B

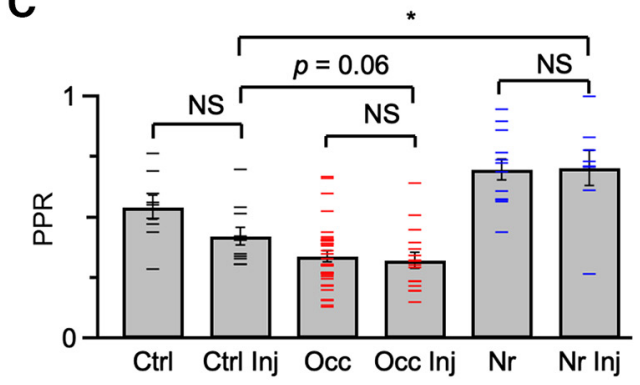

D

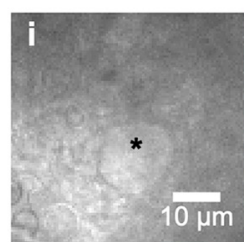

if

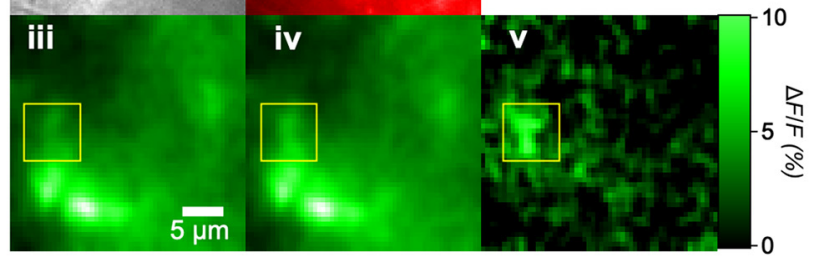

Figure 4. Effects of cochlea injection. $\boldsymbol{A}$, Representative ABR traces from a P20 control mouse (left), and a P22 injected mouse (right). Traces represent averages of 1024 responses to click stimuli. $\boldsymbol{B}$, Average ABR thresholds for control (5 ears) and after cochlear injection (6 ears). After cochlear injection, thresholds were significantly elevated $(p<0.05)$. $\boldsymbol{C}$, Measurements of PPRs at $\Delta t=3 \mathrm{~ms}$ for control, occluded, and noise-reared mice with and without cochlear injection. These results indicated that PPRs were affected by cochlea injection, but the relative effects of noise-rearing or occlusion were basically preserved (Ctrl: 9 cells; Ctrl Inj: 11 cells; $0 c c: 32$ cells; $0 c c$ Inj: 16 cells; Nr: 12 cells; Nr Inj: 8 cells). Ctrl versus Ctrl Inj: $p=0.06$; $0 c c$ versus $0 c c$ Inj: $p=0.7$; Nr versus $\mathrm{Nr}$ inj: $p=0.9$; Ctrl Inj versus $0 c c$ Inj: $p=0.06$; Ctrl inj versus $\mathrm{Nr}$ Inj: $p=0.006$. $D$, Representative images confirming BC ( $\boldsymbol{D i}$, brightfield) and presynaptic endbulb, labeled by dextran-conjugated Texas red (Dii, red). Green images represent calcium green-1 fluorescence before (Diii) and after (Div) single stimulation. $D \boldsymbol{v}$, Stimulation-induced changes in fluorescence. Yellow box represents region with large fluorescence changes. The other regions of the endbulb represent negligible fluorescence changes. ${ }^{*} p<0.05$, NS $=$ not significant $(p>0.05)$.

We measured fluorescence changes in response to paired stimulation in endbulbs from control (Fig. 5Ai), occluded (Fig. $5 \mathrm{Bi}$ ), and noise-reared mice (Fig. $5 \mathrm{Ci}$ ). We quantified the amplitudes of the first fluorescence transient $\left(\right.$ Peak $\left._{1}\right)$ and the second $\left(\mathrm{Peak}_{2}\right)$ after subtracting the single-stimulus waveform (Fig. 5Aii, Bii,Cii). A low value of $\mathrm{Peak}_{2} / \mathrm{Peak}_{1}$ would be indicative of saturation.

To assess the concentration of calcium green-1 at endbulbs, we also measured the decay $\tau$ of transients. Peak ${ }_{1}$ and Peak pere $_{2}$ nearly the same amplitude in control and noise-reared endbulbs for all rates of decay (Fig. 5Aii,Aiii,Cii,Ciii). After occlusion, however, the relative amplitude of $\mathrm{Peak}_{2}$ was significantly reduced for endbulbs with $\tau$ faster than $40 \mathrm{~ms}$ (Fig. 5Bii,Biii). This suggests that endbulbs with low indicator concentrations could be identified by showing a decay $\tau$ faster than $40 \mathrm{~ms}$. Occluded endbulbs with decay $\tau<40$ ms showed significantly greater saturation than control or noise-reared endbulbs (Ctrl: Peak $2 /$ Peak $_{1}=0.98 \pm 0.03,27$ cells; Occ: $0.84 \pm 0.03,16$ cells, $p=0.0008$; Nr: $1.03 \pm 0.02,21$ cells, $p=0.2$ ). This suggests that $\mathrm{Ca}^{2+}$ influx increased following occlusion.

In addition, we tested whether activitydependent changes in PPR might result from changes in $\mathrm{Ca}^{2+}$ handling in endbulbs. There was no systematic change in the $\tau$ of decay for Peak ${ }_{1}$ averaged across all endbulbs for each acoustic condition (Ctrl: $\tau=34.9 \pm 3.0 \mathrm{~ms}, 35$ cells; Occ: $\tau=$ $35.5 \pm 2.7 \mathrm{~ms}, 25$ cells, $p=0.87$; $\mathrm{Nr}: \tau=$ $34.3 \pm 2.2 \mathrm{~ms}, 27$ cells, $p=0.88$ ) (Fig. $5 A-$ $C)$. It is possible this comparison was confounded by endbulbs that were overloaded with calcium green-1. We therefore selected endbulbs where Peak ${ }_{1}$ had a fast decay $(\tau<40 \mathrm{~ms})$ and assessed the decay of Peak ${ }_{2}$. However, we did not detect a systematic change under any acoustic condition (Fig. 5D). Furthermore, the slight slowing of the decay tau for the second pulse ( $\sim 5 \mathrm{~ms}$ across all conditions) is consistent with the $\mathrm{Ca}^{2+}$ indicator being near saturation (model results not shown). This suggests that there were no activity-dependent changes in factors that influence $\mathrm{Ca}^{2+}$ clearance, including surface-to-volume ratio, buffering, or extrusion rate.

As a second test of changes in $\mathrm{Ca}^{2+}$ influx, we quantified the amplitudes of $\mathrm{Ca}^{2+}$ transients after single stimuli for endbulbs exposed to the different acoustic conditions, and found no significant differences in Peak ${ }_{1}$ (Ctrl: $\Delta F / F=0.42 \pm$ $0.04 \%, 27$ cells; Occ: $0.38 \pm 0.04 \%, 16$ cells, $p=0.60$; Nr: $0.43 \pm 0.04 \%, 21$ cells, $p=0.87$ ) (Fig. $5 E$ ), suggesting that total influx of $\mathrm{Ca}^{2+}$ in the endbulb did not change. However, the interpretation of this measurement is complicated by activity-dependent changes in endbulb structure. Previous work indicated that the size of the vesicle pool increased after noiserearing (Ngodup et al., 2015), whereas after occlusion the number of release sites decreased (Zhuang et al., 2017). These changes in number of release sites are the opposite of predicted changes in $\mathrm{Ca}^{2+}$ influx at single release sites, and it is possible that the net result is similar total fluorescence signals after a single stimulation.

With pairs of pulses, we did not detect a decrease in saturation after noise-rearing (Fig. $5 \mathrm{C}$ ), perhaps because control endbulbs showed little saturation to begin with. To enhance the sensitivity of this approach, we stimulated ANFs with a train of 10 stimuli at $100 \mathrm{~Hz}$ (Fig. $5 F$ ). $\mathrm{Ca}^{2+}$ transients built up significantly more after ear occlusion, but less after noise-rearing (Fig. 5G; Ctrl: 14 cells; Occ: 11 cells, $p=0.03$; Nr: 14 cells, $p=0.01$ ), suggesting that overall $\mathrm{Ca}^{2+}$ influx increases after occlusion and decreases after noise-rearing. To measure individual peak amplitudes, the subtraction method used in Figure $5 A-C$ was not 
Ai $\mathrm{Crr}$

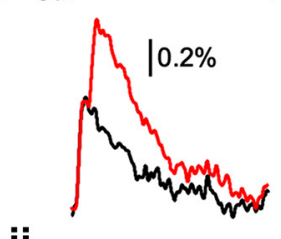

ii<smiles>CCCC1CCCCC1C</smiles>

iii

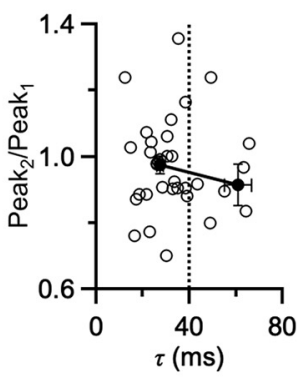

F

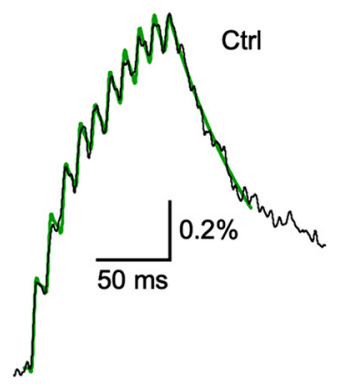

Bi Occ

ii

iii
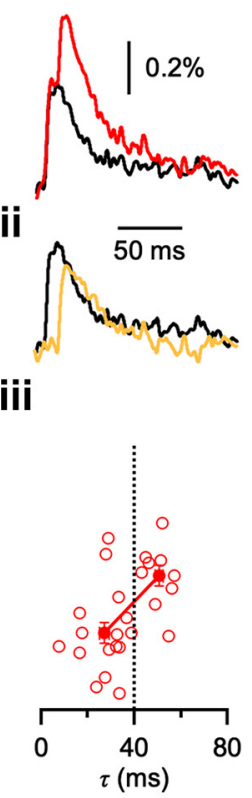

G
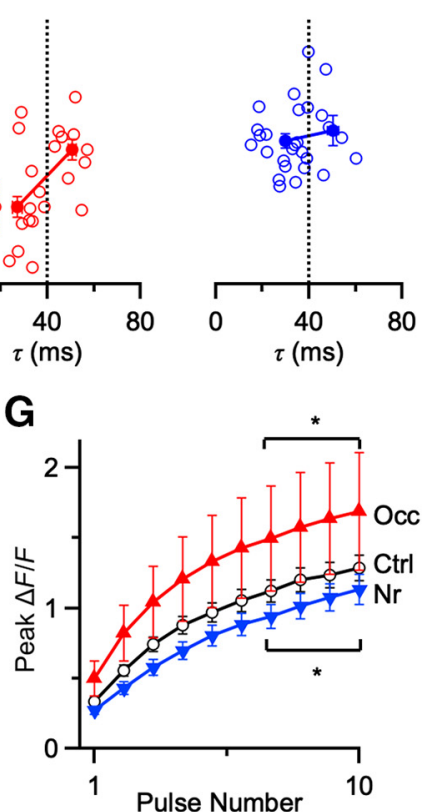

D

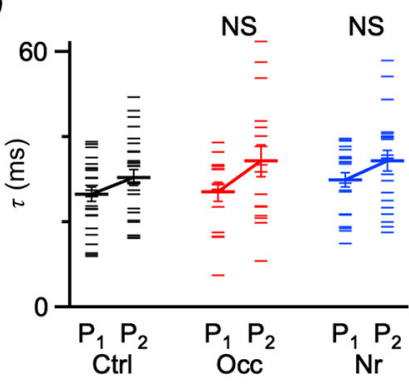

E

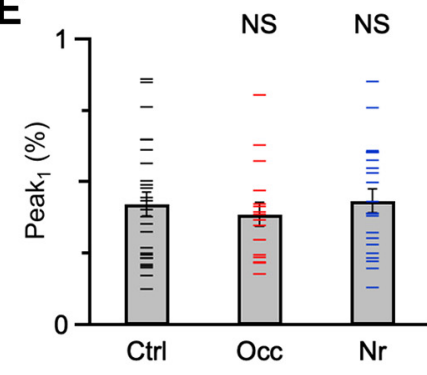

H

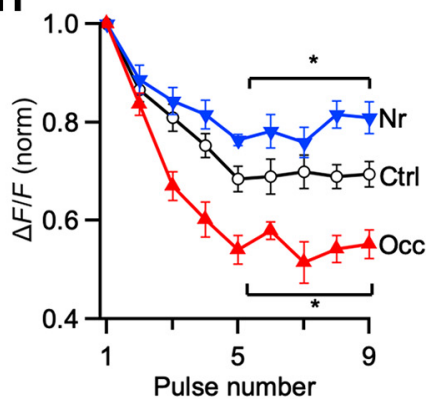

Figure 5. Changes in $\mathrm{Ca}^{2+}$ influx. $A-C, \mathrm{Ca}^{2+}$-fluorescence transients are recorded with photodiode and evoked by one stimulus (black) and paired stimuli ( $\Delta t=10 \mathrm{~ms}$, red) from control $(\boldsymbol{A} \boldsymbol{i})$, occluded $(\boldsymbol{B} \boldsymbol{i})$, and noise-reared $(\boldsymbol{C} \boldsymbol{i})$ endbulbs. Middle traces $(\boldsymbol{A i i}, \boldsymbol{B i i}$, Cii) represent the single stimulation (black) compared with the subtracted response, showing only response to the second pulse (yellow). Every trace represents an average of 15-20 trials. Bottom panels (Aiii, Biii, Ciii) represent the amplitude of the second peak normalized to the first (Peak $2 /$ Peak $_{1}$ ) for transients of different decay rate constants $(\tau)$. Occluded endbulbs $(\boldsymbol{B})$ with $\tau$ faster than $40 \mathrm{~ms}$ showed evidence of saturation (Peak 2 /Peak $\mathrm{k}_{1}<1$ ), indicating that calcium levels approached the $K_{D}$ of calcium green-1 (25 cells). Occluded endbulbs with $\tau$ slower than $40 \mathrm{~ms}$ did not show saturation (Peak $/$ Peak $_{1}$ near 1 ), indicating that they were overloaded. Saturation was significantly lower in control and noise-reared endbulbs, indicating lower $\mathrm{Ca}^{2+}$ influx. Dashed line at $40 \mathrm{~ms}$ indicates maximal decay tau for data used in analyses in $\boldsymbol{D}-\boldsymbol{H}$. $\boldsymbol{D}$, Decay $\tau$ of Peak ${ }_{1}$ and Peak ${ }_{2}$ from control, occluded, and noise-reared endbulbs. (Ctrl: 27 cells; 0cc: 16 cells; Nr: 21 cells). $E$, Average Peak amplitudes from three conditions. Peak amplitudes from endbulbs of occluded and noise-reared mice are not significantly different from control $(p>0.05)$. F, Representative $\mathrm{Ca}^{2+}$ transient from a P20 control mouse following 10 pulses of $100 \mathrm{~Hz}$ stimulation. Black trace represents the average of 12 trials. Green trace represents a fit for measuring peak amplitudes (see Results). $\mathbf{G}$, Average peak fluorescence during trains for different acoustic conditions $\left({ }^{*} p<0.05\right)$. $\boldsymbol{H}$, Average step increases in fluorescence for peaks $1-9$ from three acoustic conditions (11-14 cells each condition). ${ }^{*} p<0.05$, NS $=$ not significant $(p>0.05)$.

practical. Instead, we fit transients to an equation of the form: $y(t)=\sum_{i} A_{i} e^{-\left(t-t_{i}\right) / \tau} H\left(t-t_{i}\right)$, where $A_{i}$ and $t_{i}$ are the time and amplitude of each pulse, $\tau$ is the rate of decay, and $H$ is the unit step function. This equation appeared reliable at reporting individual peak amplitudes (Fig. 5F, green), except for the final pulse, which was consistently underestimated. After ear occlusion, the amplitudes of pulses 5-9 decreased significantly, indicating saturation significantly increased; and after noise-rearing, their amplitudes significantly increased, indicating saturation significantly decreased (Fig. $5 H$; Ctrl: 14 cells; Occ: 11 cells; $p<0.001$; Nr: 14 cells; $p<0.001)$. This is best explained by increased $\mathrm{Ca}^{2+}$ influx after ear occlusion and decreased $\mathrm{Ca}^{2+}$ influx after noiserearing.

\section{$\mathrm{Ca}^{2+}$ efficacy}

Another potential contribution to changes in $P_{\mathrm{r}}$ is the efficacy of $\mathrm{Ca}^{2+}$ after influx within $\mathrm{Ca}^{2+}$ domains. We assessed changes in how $\mathrm{Ca}^{2+}$ drives neurotransmitter release by plotting normalized EPSC amplitude in multiple external $\mathrm{Ca}^{2+}$ concentrations $\left(\mathrm{Ca}_{\mathrm{e}}\right)$ against $\mathrm{Ca}^{2+}$ influx $\left(\mathrm{Ca}_{\mathrm{in}}\right)$ and fitting the relationship to a power law: EPSC $=k\left[\mathrm{Ca}_{\mathrm{in}}\right]^{n}$. The exponent $n$ is called the cooperativity, and is sensitive to coupling efficacy between $\mathrm{Ca}^{2+}$ and neurotransmitter release (Dodge and Rahamimoff, 1967). We measured EPSC ${ }_{1}$ amplitude over 0.54.5 $\mathrm{Ca}_{\mathrm{e}}$ (Fig. 6A,B). To avoid saturation of postsynaptic AMPA receptors, we measured EPSCs in the presence of 1 $\mathrm{mM}$ kynurenate. We also measured relative $\mathrm{Ca}_{\text {in }}$ across the same range of $\mathrm{Ca}_{\mathrm{e}}$ (Fig. $6 C, D$ ). To avoid saturation of the indicator, we overloaded cochleas with twice the usual volume of indicator and restricted our analysis to cells that had $\mathrm{Peak}_{2} /$ Peak $_{1}$ close to 1 at all $\mathrm{Ca}_{\mathrm{e}}$. We plotted the normalized $\mathrm{EPSC}_{1}$ against $\mathrm{Ca}_{\text {in }}$, and saw almost perfect overlap across all acoustic conditions (Fig. 6E), with one exception. Occluded synapses in $4.5 \mathrm{Ca}_{\mathrm{e}}$ were far to the right of the other points. It is possible that this reflects saturation of the release process because this 

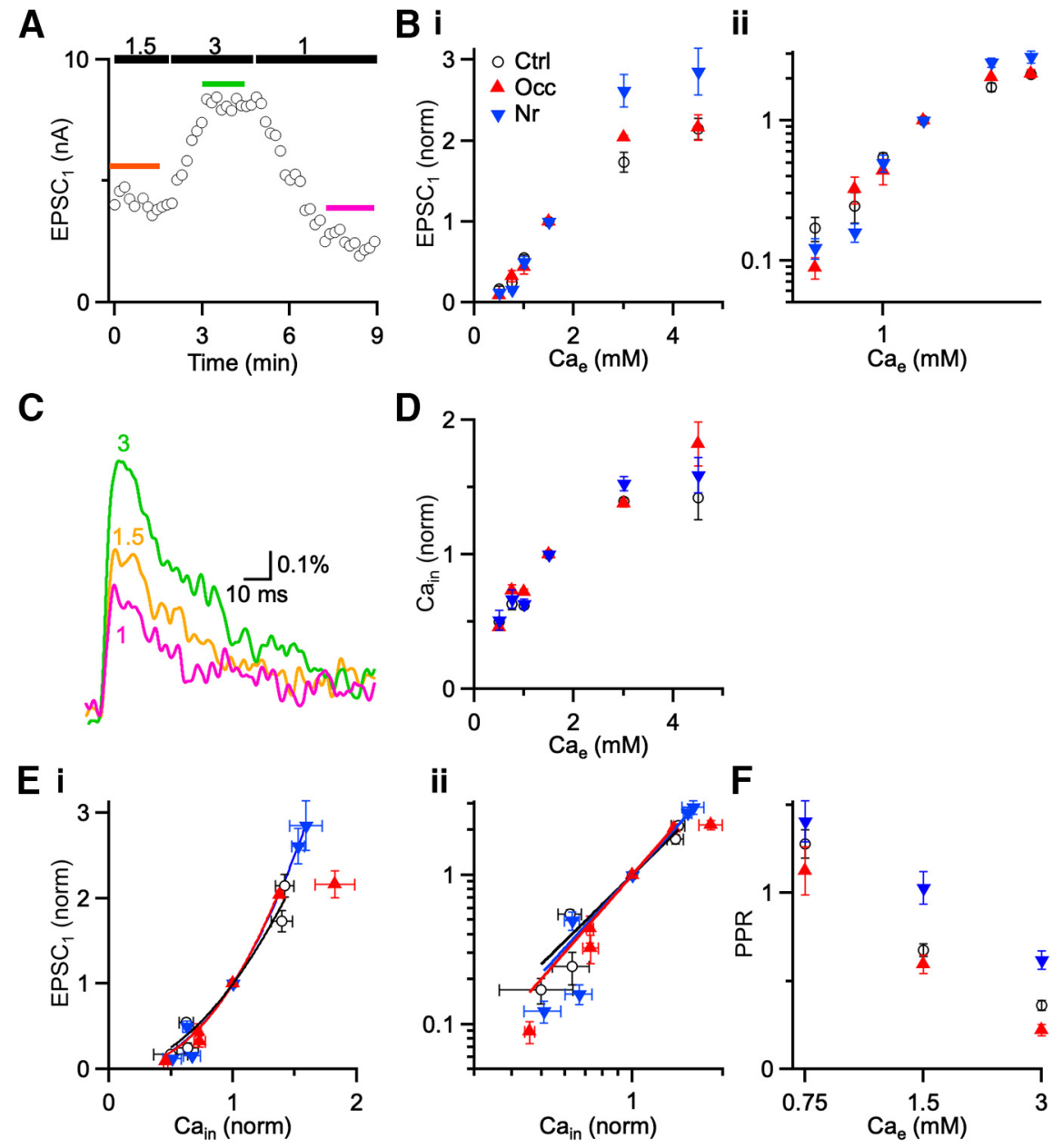

Figure 6. No change in $\mathrm{Ca}^{2+}$ cooperativity. $\boldsymbol{A}$, Representative experiment showing effects of $\mathrm{Ca}_{\mathrm{e}}(1,1.5$, and $3 \mathrm{mM})$ on EPSC amplitudes from a control mouse (P21) in the presence of kynurenate. Markers represent EPSC ${ }_{1}$ peak amplitude on each trial. Colored lines above the points indicate the data that are averaged for analysis. $\boldsymbol{B}$, Average EPSC amplitude from voltage-clamp experiments (8 cells) as a function of $\mathrm{Ca}_{\mathrm{e}}$ on linear (Bi) and $\log -\log (\boldsymbol{B i i})$ axes. $\boldsymbol{C}$, Average $\Delta F / F$ transients at a representative endbulb following single stimuli in different $\mathrm{Ca}_{\mathrm{e}}$. Traces are averages of 10-15 trials. $\boldsymbol{D}, \mathrm{C}^{2+}{ }^{2+}$ influx $\left(\mathrm{C}_{\mathrm{in}}\right)$ from imaging experiments ( 6 cells) in different $C_{a}$ for different acoustic conditions. $C_{\text {in }}$ was normalized to peak $\Delta F / F$ in $1.5 \mathrm{mM}$ $C_{\mathrm{e}} . \boldsymbol{E}_{,} \mathrm{Ca}^{2+}$ cooperativity. Points are EPSC ${ }_{1}$ data from $\boldsymbol{B}$ plotted against peak $\triangle F / F$ data from $\boldsymbol{D}$ for different acoustic conditions on linear $(\mathbf{B i})$ and $\log -\log (\mathbf{B i i})$ axes. Lines are fits to the equation EPSC $=k\left[\mathrm{Ca}_{\mathrm{in}}\right]^{n}$, where $n$ is the cooperativity (Ctrl: $n=1.97 \pm 0.15 ; \mathrm{Nr}: n=2.27 \pm 0.08 ; 0 \mathrm{ccc}: n=2.32 \pm 0.14)$. Cooperativity was not significantly different after ear occlusion or noise-rearing. $\boldsymbol{F}$, Buffer saturation and paired pulse plasticity. Points are PPR measured in different $\mathrm{Ca}_{\mathrm{e}}$ for different acoustic conditions. Points are averages of 5-27 cells. PPR decreases for all acoustic conditions, suggesting that buffer saturation plays little role at endbulbs (see Results).

point likely represents the very highest $\mathrm{Ca}^{2+}$ influx, which may run into an upper limit on neurotransmitter release (Foster et al., 2002). In any case, it appears appropriate to quantify cooperativity without this extreme point. We fitted the results to the power law equation (Fig. 6E, lines), which indicates that cooperativity of $\mathrm{Ca}^{2+}$ did not change significantly after ear occlusion or noise-rearing (Ctrl: $n=1.97 \pm$ 0.15 ; Occ: $n=2.32 \pm 0.14$; Nr: $n=2.27 \pm 0.08,5-20$ experiments for each value).

The efficacy of $\mathrm{Ca}^{2+}$ at driving neurotransmitter release has also been suggested to be influenced by the endogenous $\mathrm{Ca}^{2+}$ buffer. In this model (Blatow et al., 2003), $\mathrm{Ca}^{2+}$ influx during one action potential may be diverted by a high-affinity, endogenous $\mathrm{Ca}^{2+}$ buffer, thereby effectively reducing neurotransmitter release. When a second action potential occurs and the buffer remains partially occupied, more of the $\mathrm{Ca}^{2+}$ influx can drive neurotransmitter release, which is observable as facilitation. Thus, noise rearing may increase PPR through enhanced $\mathrm{Ca}^{2+}$ buffering. A key prediction of the buffer-saturation model is that higher $\mathrm{Ca}_{\mathrm{e}}$ should increase $\mathrm{Ca}^{2+}$ influx, which enhances buffer saturation and facilitation (Jackman et al., 2016). However, we found that PPR decreased with greater $\mathrm{Ca}_{e}$ for all endbulbs regardless of acoustic experience (Fig. 6F; 5-27 cells per point), suggesting that changes in endogenous buffer saturation are unlikely to account for changes in PPR (two-way ANOVA followed by Tukey's test: $1.5 \mathrm{Ca}_{\mathrm{e}}$ vs $3 \mathrm{Ca}_{\mathrm{e}}, p<0.001$; $1.5 \mathrm{Ca}_{\mathrm{e}} \quad$ vs $\left.0.75 \mathrm{Ca}_{\mathrm{e}}, \quad p<0.001\right)$. Furthermore, PPR changed significantly in different acoustic conditions at these additional $\mathrm{Ca}_{\mathrm{e}}$ (two-way ANOVA followed by Tukey's test: Occ vs Ctrl: $p<0.01 ; \mathrm{Nr}$ vs Ctrl: $p<0.001$ ). These data reinforce that presynaptic $\mathrm{Ca}^{2+}$ influx is the primary driver in regulating $P_{\mathrm{r}}$ under different acoustic conditions.

\section{Model of $\mathrm{Ca}^{2+}$ influx}

We wanted to know whether acoustically driven changes in $\mathrm{Ca}^{2+}$ influx were sufficient to account for changes in PPR. To test this, we first tried to estimate the changes in $\mathrm{Ca}^{2+}$ influx from the saturation data. We did this by modeling $\mathrm{Ca}^{2+}$ influx as a step increase $\left(\mathrm{Ca}_{\text {peak }}\right)$ over resting $\mathrm{Ca}^{2+}$ $\left(\mathrm{Ca}_{\text {rest }}\right)$ for each pulse $i$ of the train, followed by an exponential decay $(\tau): \mathrm{Ca}(t)=$ $C a_{\text {rest }}+\sum_{i} C a_{\text {peak }} e^{-\left(t-t_{i}\right) / \tau} H\left(t-t_{i}\right) . \quad$ An example is illustrated in Figure $7 A$ (top). This neglects the extremely large and fastdecaying local $\mathrm{Ca}^{2+}$ that drives neurotransmitter release, which would not be detected by the indicator.

The indicator was then modeled using two fixed parameters: $K_{\mathrm{D}}$ and the relative increase in brightness of the indicator on binding $\mathrm{Ca}^{2+}, B$. The fluorescence, $F$, of the indicator depends on $\mathrm{Ca}^{2+}$, as given by the following: $F(C a)=\left(K_{\mathrm{D}}+B C a\right) /\left(K_{\mathrm{D}}+C a\right)$. We set $K_{\mathrm{D}}=540 \mathrm{nM}$ and $B=15$ to match the reported characteristics of calcium-green 1 (Haugland, 1996; Kreitzer et al., 2000). Then we mimicked the $\Delta F / F$ measurements using: $\Delta F / F(C a)=F(C a) / F\left(C a_{\text {rest }}\right)-1$, and filtered at $250 \mathrm{~Hz}$, which is near the frequency response of the photodiode. This yielded traces as in Figure 7A (bottom, green lines). As predicted, the increase in $\triangle F / F$ was largest for the first peak because of saturation of the dye.

We next fit the model to measured $\Delta F / F$ trains, with $\mathrm{Ca}_{\text {peak }}$, $\mathrm{Ca}_{\text {rest }}$, and $\tau$ as free parameters. An example is shown in Figure $7 \mathrm{~A}$ (bottom) $\left(\mathrm{Ca}_{\text {peak }}=50.9 \mathrm{nM}, \mathrm{Ca}_{\text {rest }}=67.1 \mathrm{nM}\right.$, and $\tau=$ $52.6 \mathrm{~ms})$. The quality of the fit was quite high with just three free parameters. $\mathrm{Ca}_{\text {peak }}$ was generally far below the $K_{\mathrm{D}}$ of the dye, consistent with modest levels of saturation. $\mathrm{Ca}_{\text {rest }}$ and $\mathrm{Ca}_{\text {peak }}$ were of a similar order of magnitude, consistent with the small $\Delta F / F$ values and small areas of endbulb with $\mathrm{Ca}^{2+}$ influx. We compared the measured $\Delta F / F$ peak amplitudes from Figure $5 H$ 
(Fig. $7 B$, points) to the predicted peak amplitudes from the model (Fig. $7 B$, lines), and there was a good match. The average parameters for control trains were $\mathrm{Ca}_{\text {peak }}=$ $43.2 \pm 4.1 \mathrm{nM}, \mathrm{Ca}_{\text {rest }}=73.5 \pm 13.6 \mathrm{nM}, \tau=$ $55.6 \pm 1.6 \mathrm{~ms} \quad(n=14) ; \quad$ for noise-reared, $\mathrm{Ca}_{\text {peak }}=23.7 \pm 2.7 \mathrm{nM}, \mathrm{Ca}_{\text {rest }}=53.9 \pm 12.6$ $\mathrm{nM}, \tau=62.6 \pm 2.8 \mathrm{~ms} \quad(n=14)$; and for occluded, $\mathrm{Ca}_{\text {peak }}=93.3 \pm 9.87 \mathrm{nM}, \mathrm{Ca}_{\text {rest }}=$ $127 \pm 24 \mathrm{nM}, \tau=53.9 \pm 1.4 \mathrm{~ms} \quad(n=11)$. These fits are consistent with $\mathrm{Ca}_{\text {peak }}$ decreasing after noise-rearing, and increasing after occlusion (Fig. 7C), as suggested by our physiology and imaging results.

We next compared the impact of $\mathrm{Ca}^{2+}$ influx on PPR for changes in different acoustic conditions versus $\mathrm{Ca}_{\mathrm{e}}$ (Fig. 7D). The acoustic data (solid, red markers) summarize the estimated $\mathrm{Ca}^{2+}$ influx from Figure $7 C$ normalized to control, and the average PPR data from Figure $4 C$ (injected). As expected, PPR was inversely correlated with $\mathrm{Ca}^{2+}$ influx. We compared this relationship with the effects of different $\mathrm{Ca}_{\mathrm{e}}$ on PPR of control synapses (open, black markers), which summarizes PPR and $\mathrm{Ca}^{2+}$ measurements from the experiments of Figure 6. These two curves overlap considerably, indicating that changes in $\mathrm{Ca}^{2+}$ influx cause changes in depression, whether those changes in influx are driven by acoustic conditions or simple changes in $\mathrm{Ca}_{\mathrm{e}}$. The similarity in dependence suggests furthermore that changes in $\mathrm{Ca}^{2+}$ influx in response to acoustic conditions are sufficient to explain changes in levels of depression.

\section{Calcium channel composition}

Our experiments support the conclusion that activity-dependent changes in PPR at endbulbs result from changes in $\mathrm{Ca}^{2+}$ influx. To begin to understand the basis for changes in $\mathrm{Ca}^{2+}$ influx, we identified the $\mathrm{Ca}^{2+}$ channel subtypes driving neurotransmitter release using subtype-specific antagonists. In immature endbulbs, neurotransmitter release is driven primarily by $\mathrm{P}$-/Q-type $\mathrm{Ca}^{2+}$ channels, with a smaller contribution from N-type (Oleskevich and Walmsley, 2002). We examined how this might change in different acoustic conditions in older endbulbs. In the presence of kynurenate, we applied $\omega$-agatoxin IVA $(200 \mathrm{nM})$, which is an antagonist of P-/Q-type $\mathrm{Ca}^{2+}$ channels (Fig. 8A). In endbulbs from both control and noise-reared mice, agatoxin blocked EPSCs nearly completely (Ctrl: $94 \pm 2 \%, 7$ cells; Nr: $93 \pm 3 \%$, 8 cells; $p=0.46$; Fig. $8 C$ ). In endbulbs from occluded mice, block by agatoxin was significantly lower (Occ: $78 \pm 7 \%, 10$ cells, $p=0.048$; Fig. $8 C$ ), suggesting that $\mathrm{P}$-/Q-type $\mathrm{Ca}^{2+}$ channels play a smaller role in neurotransmitter release after ligation.

We also applied $\omega$-conotoxin GVIA $(0.5 \mu \mathrm{M})$, which is an antagonist against $\mathrm{N}$-type $\mathrm{Ca}^{2+}$ channels (Fig. $8 B$ ). In endbulbs from control and noise-reared mice, conotoxin blocked EPSCs to a small extent (Ctrl: $32 \pm 6 \%, 11$ cells; Nr: $22 \pm 7 \%, 7$ cells; $p=0.15$; Fig. $8 C$ ). In endbulbs from occluded mice, block by conotoxin was greater (Occ: $51 \pm 6 \%, 6$ cells, $p<0.01$; Fig. $8 C)$, suggesting that $\mathrm{N}$-type $\mathrm{Ca}^{2+}$ channels play a larger role in
B

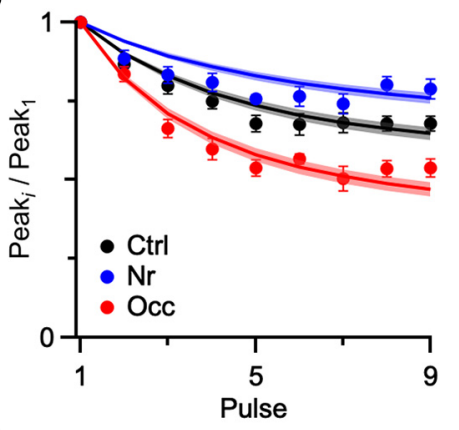

D

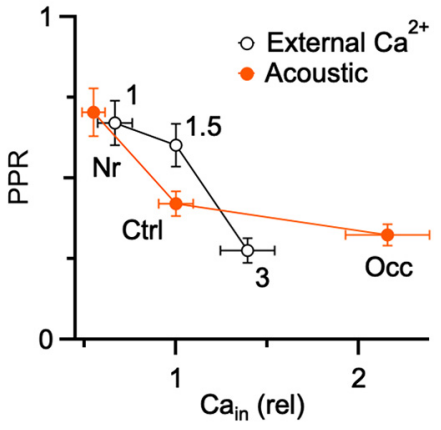

Figure 7. Comparing the effects of acoustic experience or external $\mathrm{Ca}^{2+}$ on $\mathrm{Ca}^{2+}$ influx and PPR. A, Model of $\mathrm{Ca}^{2+}$ influx (top) with $C_{a}$ peak $=50.9 \mathrm{nM}, C_{\text {rest }}=67.1 \mathrm{nM}$, and decay $\tau=52.6 \mathrm{~ms}$, and the modeled $\Delta F / F$ signal (bottom, green

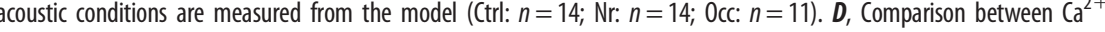
from the imaging and electrophysiology experiments of cooperativity in Figure 6. Overlap of these curves suggests that changes in $\mathrm{Ca}^{2+}$ account for acoustically-driven changes in PPR.

neurotransmitter release after occlusion. Together, these experiments suggest that the composition of $\mathrm{Ca}^{2+}$ channels involved in release is modulated by activity. This further supports the conclusion from the chelator and imaging experiments that changes in depression result from changes in $\mathrm{Ca}^{2+}$ influx.

\section{Presynaptic versus postsynaptic changes}

Changes in activity affect synaptic fidelity in fiber-stimulation experiments (Ngodup et al., 2015; Zhuang et al., 2017). In order to distinguish the contributions of presynaptic and postsynaptic changes to fidelity, we used dynamic clamp (Sharp et al., 1993). We first recorded EPSCs in voltage-clamp and stimulated single ANFs for 20 pulses at $100 \mathrm{~Hz}$ (5-8 cells for each acoustic condition) (Fig. 9A). We then selected a cell that exhibited an intermediate level of depression for each condition (Fig. 9A, color). To capture the natural variability of EPSC amplitudes, we convolved the EPSC amplitudes from 8 to 15 individual trials from the three representative cells with a standard unit conductance (Fig. 9B). We applied these conductances using two-electrode dynamic clamp (one electrode to read voltage, one electrode to pass current) (Yang et al., 2015) to BCs of mice exposed to three sound conditions and measured spiking responses (Fig. 9C-H). BCs from control, occluded, and noise-reared mice fired fewer action potentials when occluded conductances were applied (Fig. $9 F$ vs Fig. 9G), and more action potentials when noise-reared conductances were applied (Fig. $9 H$ vs Fig. $9 G$ ) compared with control 

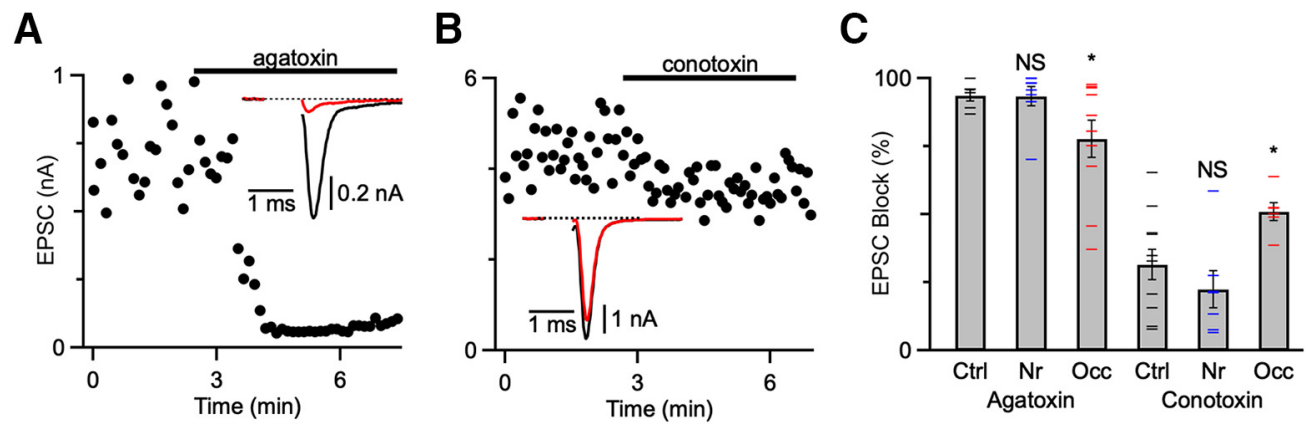

Figure 8. $\mathrm{Ca}^{2+}$ channel subunit composition. $\boldsymbol{A}, \boldsymbol{B}$, Effects of $\omega$-agatoxin IVA (A) or $\omega$-conotoxin GVIA (B) on EPSC amplitude. Markers are individual EPSC amplitudes. Recordings are from control endbulbs in the presence of kynurenate. Insets, Average EPSCs before (black) and after (red) drug application. $C$, Average effects of agatoxin and conotoxin on control, noise-reared, and occluded endbulbs. ${ }^{*} p<0.05$, NS $=$ not significant $(p>0.05)$.

conductances. We repeated these experiments in multiple BCs and quantified firing probability for pulses 11-20. Firing probability was significantly lower in response to occluded presynaptic conductances and significantly greater in response to noisereared presynaptic conductances (Fig. 9I; one-way repeatedmeasures ANOVA followed by Tukey's test, Occ: $p<0.001$; Nr: $p<0.01)$. These results indicate that changes in presynaptic conductances have an important influence on fidelity.

Considering the effect of postsynaptic changes on fidelity, BCs from occluded conditions fired fewer action potentials compared with BCs from control conditions (Fig. 9F-Hi vs Fig. 9Hii), whereas BCs from noise-reared conditions were similar to control for all presynaptic conductances (Fig. 9F-Hiii vs Fig. 9Hii). On average, BCs from noise-reared and control conditions responded similarly to the same presynaptic conductances, but occluded BCs had lower firing fidelity (one-way repeated-measures ANOVA followed by Tukey's test, Occ: $p<0.001$; Nr: $p>0.05)$. Thus, presynaptic changes after ear occlusion and noise-rearing influenced spiking fidelity, while postsynaptic changes contributed to spiking primarily after occlusion.

\section{Discussion}

We have demonstrated a critical role for presynaptic homeostatic mechanisms in vivo in regulating spike fidelity. Mature and young endbulbs are subject to similar changes in $P_{\mathrm{r}}$, suggesting that these changes are not a developmental process restricted to a critical period. Furthermore, our results strongly suggest that changes in synaptic depression result from changes in presynaptic $\mathrm{Ca}^{2+}$ influx, in part by expression of $\mathrm{Ca}^{2+}$ channel subtypes. Finally, our dynamic-clamp experiments underscore the importance of presynaptic adaptations for postsynaptic spike fidelity. Presynaptic changes following both occlusion and noise-rearing affected spike fidelity, and postsynaptic changes following only occlusion also had an effect. Thus, regulation of presynaptic $\mathrm{Ca}^{2+}$ signaling in response to acoustic activity plays a critical role in synaptic strength, raising the possibility that similar changes could be important at additional synapses and may contribute to diversity in levels of synaptic depression among synapses.

\section{Activity-dependent changes at mature endbulbs}

Our data imply that endbulbs change their properties depending on sound conditions throughout life. It is a question how such changes could contribute to the long-lasting effects of auditory activity in humans, such as how otitis media may lead to longterm processing disorders (Gates, 1996; Zhou et al., 2008; Whitton and Polley, 2011; Langguth et al., 2013). In auditory cortex, inhibitory synapses onto pyramidal neurons can be permanently altered when hearing loss occurs during a critical period (Mowery et al., 2015). This differs from our observations in the auditory brainstem that both young and mature endbulbs are subject to similar activity-dependent changes of $P_{\mathrm{r}}$, and the changes revert when normal conditions are restored (Fig. 1). One reason for these different findings may be simply that these are different synapses. BCs relay sound information to higher-order areas, and endbulbs may need to retain flexibility as cochlear activity changes into maturity (Skoe et al., 2015). Furthermore, ANFs have diverse firing rates because of their varied sound sensitivity (Liberman, 1978), so the properties of individual synapses may be optimized in specific ways. Another possible reason is that endbulbs are excitatory, so they may be subject to different homeostatic mechanisms from inhibitory cortical synapses. It will be important to establish how inhibitory synapses onto BCs are affected by acoustic conditions, as imbalances in excitation and inhibition at the beginning of the auditory pathway could have cascading effects on downstream processing, which could contribute to disorders.

\section{Activity-dependent changes in $\mathrm{Ca}^{2+}$ signaling}

Together, our data indicate that $\mathrm{Ca}^{2+}$ influx is central to the regulation of $P_{\mathrm{r}}$ at endbulbs. Under experimental conditions, changing the external $\mathrm{Ca}^{2+}$ concentration (Dodge and Rahamimoff, 1967) or manipulating $\mathrm{Ca}^{2+}$ channel expression (Lubbert et al., 2019 ) is well understood to modulate $P_{\mathrm{r}}$. Our results show that regulation of $\mathrm{Ca}^{2+}$ influx occurs in vivo following exposure to different acoustic environments and activity conditions.

We concluded that the decrease in individual peak amplitudes in Figure $5 \mathrm{H}$ arose from saturation. Another possible interpretation could be that $\mathrm{Ca}^{2+}$ influx decreases during pairs or trains of stimulation. This is unlikely because other presynaptic terminals show minimal changes in $\mathrm{Ca}^{2+}$ influx during trains (Kreitzer and Regehr, 2000; Müller et al., 2010). An electrophysiological study of $\mathrm{Ca}^{2+}$ currents in endbulbs showed either constant current during trains or modest increases (Lin et al., 2011), but these recordings were in very young animals and at room temperature, both of which could influence the dynamics of $\mathrm{Ca}^{2+}$ currents. Our data do address this alternate interpretation because some endbulbs had slow fluorescence transients, most likely because they were overloaded with calcium green- 1 . When dye is overloaded, $\mathrm{Ca}^{2+}$ levels cause linear changes in fluorescence. We found that fluorescence transients with decay $\tau>40 \mathrm{~ms}$ had identical peak height for two pulses for control (Fig. 5Aiii), noise-reared (Fig. 5Biii), and even occluded endbulbs (Fig. 5Ciii). This indicates that, when saturation was eliminated by 

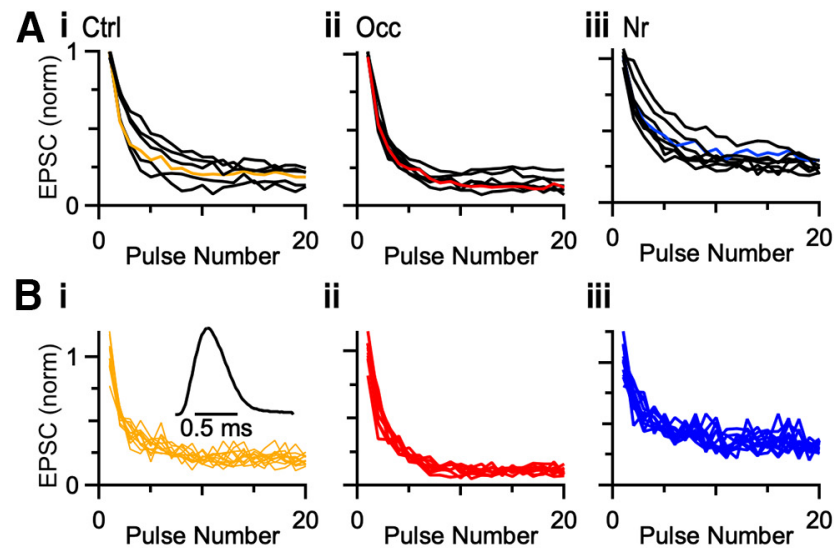

ii

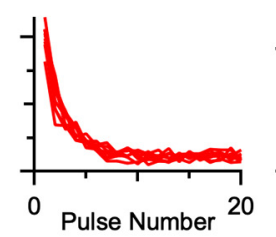

iii

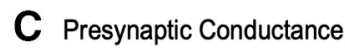

F Postsynaptic Response

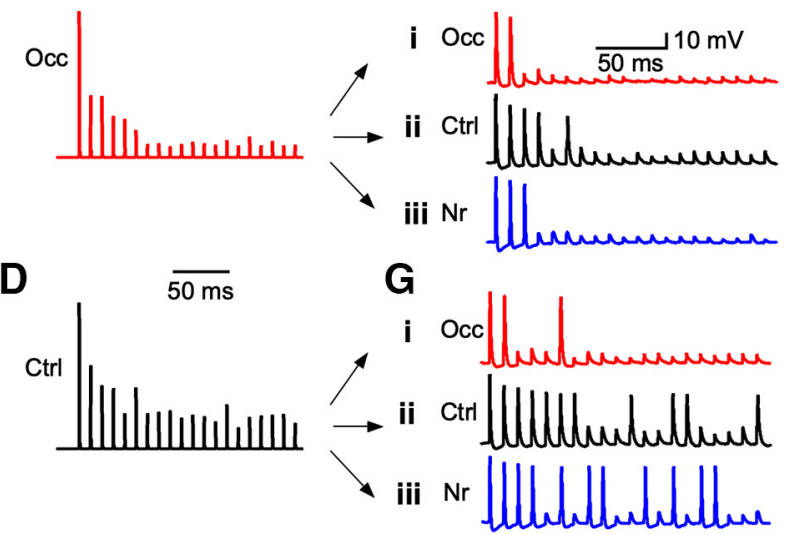

E

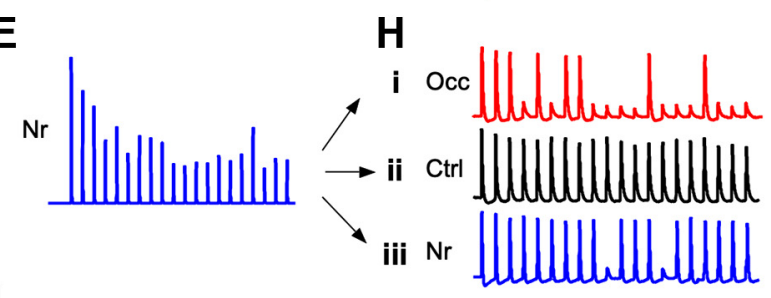

I

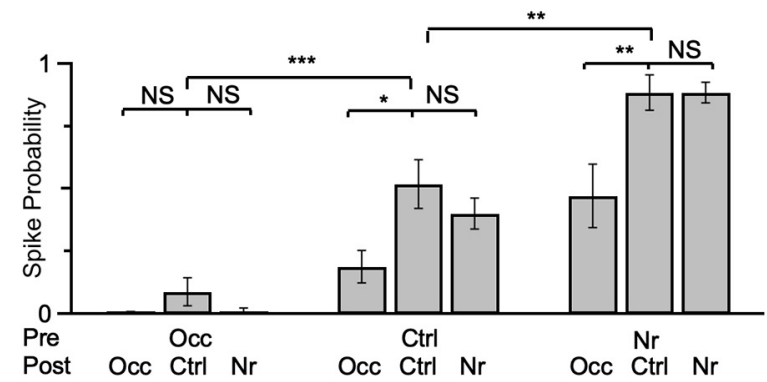

Figure 9. Presynaptic versus postsynaptic contributions to spike fidelity. $\boldsymbol{A}$, Average EPSC amplitudes from voltage-clamp experiments in response to a 20-pulse train at $100 \mathrm{~Hz}$ from (Ai) 6 control, (Aii) 7 occluded, and (Aiii) 8 noise-reared endbulbs. Data were normalized to EPSC $_{1}$. Cells with intermediate levels of synaptic depression were selected as representative cells for each acoustic condition (colored lines). $\boldsymbol{B}$, Individual trials from the representative endbulbs from different acoustic conditions in $\boldsymbol{A}$ (Ctrl: P21, 12 trials; $0 \mathrm{cc}$ : P22, 9 trials; Nr: P23, 11 trials). These individual amplitudes were convolved with a unit conductance (Bi, inset) and scaled by the threshold of the cell. $\boldsymbol{C}-\boldsymbol{E}$, Example AMPA conductances derived from data in $\boldsymbol{B}$. $\boldsymbol{F}-\boldsymbol{H}$, Examples of two-electrode dynamic-clamp recordings from occluded (i), control (ii), and noise-reared (iii) BCs after applying representative conductances in $\boldsymbol{C}-\boldsymbol{E}$. I, Spike fidelity for presynaptic conductances applied to postsynaptic BCs from three acoustic conditions. Firing probability was quantified from the last 10 stimuli of 20 pulse trains, when conductance amplitudes reach steady state. Presynaptic changes affected spike fidelity after occlusion and noise-rearing, while postsynaptic changes affected spiking primarily after occlusion. ${ }^{*} p<0.05,{ }^{* *} p<0.01,{ }^{* * *} p<0.001$, NS $=$ not significant $(p>0.05)$. overloading, $\mathrm{Ca}^{2+}$ influx did not change significantly for paired stimuli, so the best explanation for smaller peak amplitudes in Figure $5 \mathrm{H}$ is saturation; therefore, $\mathrm{Ca}^{2+}$ influx increases following occlusion and decreases following noise-rearing.

Activity-dependent changes at endbulbs are similar to presynaptic homeostatic changes at the neuromuscular junction, but there are key differences. At the neuromuscular junction, pharmacological or genetic downregulation of postsynaptic receptor activation leads to a larger vesicle pool and increased $P_{\mathrm{r}}$ through greater presynaptic $\mathrm{Ca}^{2+}$ influx within tens of minutes (Müller and Davis, 2012; Gratz et al., 2019). A similar mechanism has been described at cerebellar mossy fibers (Delvendahl et al., 2019). Activity-dependent changes at endbulbs also involve presynaptic changes in vesicle pool size and $P_{\mathrm{r}}$, most likely from changes in $\mathrm{Ca}^{2+}$ influx. However, the changes at endbulbs last for at least several hours in acute brain slices. In addition, $P_{\mathrm{r}}$ and vesicle pool size change in opposite ways (Ngodup et al., 2015; Zhuang et al., 2017), leaving $\mathrm{EPSC}_{1}$ amplitude relatively stable (Figs. $1 D, 2 D, 3 E$ ). This suggests that there are significant differences in function and signaling pathways involved. Furthermore, endbulbs change in response to manipulations that are encountered in natural, nontraumatic sensory experience, suggesting that regulation of $P_{\mathrm{r}}$ is important in vivo.

$\mathrm{Ca}^{2+}$ influx could be modulated directly by multiple factors, such as the number of channels, subunit composition, or singlechannel conductance, for example, through regulatory domains (Mochida et al., 2008; Lubbert et al., 2019). At the Drosophila neuromuscular junction, postsynaptic activity appears to influence presynaptic $\mathrm{Ca}^{2+}$ influx, at least in part, by changes in $\mathrm{Ca}^{2+}$ channel expression (Müller and Davis, 2012; Gratz et al., 2019). At endbulbs, we found that the contributions of N- and P-/Q-type channels to vesicle release changed after occlusion (Fig. 8), most likely reflecting changes in expression. $\mathrm{Ca}^{2+}$ currents can themselves facilitate or depress with repeated activation, depending on the channel subtype (Ishikawa et al., 2005; Mochida et al., 2008). However, this phenomenon is unlikely to underlie the changes we see in PPR, as $\mathrm{Ca}^{2+}$ influx appears relatively constant during paired-pulse facilitation or depression in mature synapses (Müller et al., 2010; Jackman et al., 2016). Furthermore, it would be interesting to examine whether different classes of endbulbs vary in how they modulate their $\mathrm{Ca}^{2+}$ channel composition, and whether R-type $\mathrm{Ca}^{2+}$ channels are also modulated.

$\mathrm{Ca}^{2+}$ influx could also be indirectly modulated through the shape of presynaptic action potentials (Marcotti et al., 2003; Bean, 2007). Another possibility is by neuromodulation, for example, by activation of $\mathrm{GABA}_{B}$ receptors, which influence presynaptic $\mathrm{Ca}^{2+}$ influx (Chanda and Xu-Friedman, 2010b; Chanda et al., 2011).

While $\mathrm{Ca}^{2+}$ influx seems most likely to account for activitydependent changes in PPR, the model of Figure 7 suggests that resting $\mathrm{Ca}^{2+}$ could also contribute. Indeed, a decrease in resting $\mathrm{Ca}^{2+}$ would be predicted to reduce $P_{\mathrm{r}}$ and increase block by exogenous chelators, as we observed after noise-rearing (Figs. 1-3). An increase in resting $\mathrm{Ca}^{2+}$ would be predicted to increase $P_{\mathrm{r}}$ and decrease block by exogenous chelators, as we observed after occlusion (Figs. 1-3). The changes in $\mathrm{Ca}^{2+}$ channel composition we observed in Figure 8 suggest a central role for changes in $\mathrm{Ca}^{2+}$ influx, but additional experiments will be needed to determine the relative contribution of resting $\mathrm{Ca}^{2+}$.

Many additional factors could also influence $\mathrm{Ca}^{2+}$ signaling, including the coupling distance between $\mathrm{Ca}^{2+}$ channels and $\mathrm{Ca}^{2+}$ sensors responsible for neurotransmitter release, and the intrinsic $\mathrm{Ca}^{2+}$ sensitivity of release. A number of studies have 
shown that $\mathrm{Ca}^{2+}$ channels are loosely coupled to neurotransmitter release during early development, but the association becomes tighter as synapses mature (Ohana and Sakmann, 1998; Meinrenken et al., 2002; Fedchyshyn and Wang, 2005; Wang et al., 2008), raising the possibility that this could be modulated in mature synapses. The coupling between $\mathrm{Ca}^{2+}$ channels and the release apparatus has been implicated in the diversity of structure and $P_{\mathrm{r}}$ at the calyx of Held (Fekete et al., 2019). $\mathrm{Ca}^{2+}$ cooperativity is expected to be lower when coupling is tight and higher when coupling is loose (Eggermann et al., 2011; Matveev et al., 2011). We measured $\mathrm{Ca}^{2+}$ cooperativity by changing the external $\mathrm{Ca}^{2+}$ concentration, which would affect $\mathrm{Ca}^{2+}$ influx through all activated $\mathrm{Ca}^{2+}$ channels, similar to changes in action potential duration. Thus, cooperativity is a combination of coupling distance and intrinsic sensitivity: When coupling is tight, cooperativity can reflect intrinsic sensitivity of the $\mathrm{Ca}^{2+}$ sensor for release; but when coupling is loose, the relationship is also influenced by overlap from $\mathrm{Ca}^{2+}$ domains around nearby channels (Borst and Sakmann, 1996; Sabatini and Regehr, 1997; Fedchyshyn and Wang, 2005). We saw no change in cooperativity, which suggests that mature endbulbs do not modulate their coupling distance in response to activity.

Cooperativity can also be assessed using uncaging or $\mathrm{Ca}^{2+}$ channel antagonists (Fedchyshyn and Wang, 2005; Wang et al., 2008; Jarsky et al., 2010), but these probe different aspects of release. Antagonists also can reduce the effective number of releasable vesicles (i.e., $N$ ) by preventing influx through their associated $\mathrm{Ca}^{2+}$ channels, so this approach does not simply address coupling distance. The uncaging approach is ideal for assessing the intrinsic $\mathrm{Ca}^{2+}$ sensitivity of release (Kochubey et al., 2009), which could yield information about changes in the molecular composition of the release apparatus. It is possible that coupling and intrinsic sensitivity changed in complementary ways, such that cooperativity remained constant in endbulbs. In this case, it seems unlikely that either could account for activitydependent changes in $P_{\mathrm{r}}$.

\section{Postsynaptic receptors}

Studies at other synapses have found that activity can cause changes in postsynaptic receptors in vivo (Hengen et al., 2013; Keck et al., 2013). In auditory cortex, sound deprivation can cause changes in spontaneous mIPSCs (Mowery et al., 2015). At endbulbs, anatomic data suggest that sound deprivation triggers an increase in glutamate receptor expression (Clarkson et al., 2016), and glutamate receptor mutants have impaired adaptation to auditory deprivation (Garcia-Hernandez et al., 2017). However, our early studies observed no changes in mEPSCs at endbulbs after noise-rearing or occlusion, although there were postsynaptic changes in excitability (Ngodup et al., 2015; Zhuang et al., 2017), which likely affect fidelity of spiking after occlusion in the dynamic-clamp experiments of Figure 9.

\section{Mechanisms of the diversity of $\boldsymbol{P}_{\mathbf{r}}$}

The presynaptic mechanism we have found may also help to account for the natural variability of $P_{\mathrm{r}}$ across different synapses. For example, climbing fiber and parallel fiber synapses in cerebellum have different $P_{\mathrm{r}}$ (Konnerth et al., 1990; Perkel et al., 1990), which is not explained by simple ultrastructural differences (Xu-Friedman et al., 2001), so additional factors must play a role. Among endbulbs, in vitro experiments indicate that $P_{\mathrm{r}}$ varies considerably (Yang and Xu-Friedman, 2009), which could relate to differences in activity. In vivo, ANFs vary in firing rate and sensitivity to sound (Pfeiffer and Kiang, 1965; Liberman,
1978). The homeostatic mechanism examined here would cause low-activity fibers (high sound-level threshold) to have higher presynaptic $\mathrm{Ca}^{2+}$ influx and $P_{\mathrm{r}}$, whereas high-activity fibers (low threshold) would have lower $\mathrm{Ca}^{2+}$ influx and $P_{\mathrm{r}}$. Thus, diversity in intensity sensitivity, combined with the homeostatic mechanism studied here, could account for diversity in $P_{\mathrm{r}}$.

Clearly, other factors besides activity contribute to $P_{\mathrm{r}}$. A single axon can contact different targets with each synapse exhibiting different $P_{\mathrm{r}}$, a phenomenon referred to as target-cell-specific synaptic plasticity (Reyes et al., 1998). For example, synapses formed by ANFs onto BCs show depression (high $P_{\mathrm{r}}$ ), whereas synapses formed by ANFs onto T-stellate cells show facilitation (low $P_{\mathrm{r}}$ ) (Cao and Oertel, 2010; Chanda and Xu-Friedman, 2010b). This difference in $P_{\mathrm{r}}$ cannot be simply explained by activity dependence. It will be important to determine the cellular mechanisms by which postsynaptic identity contributes to diversity in $P_{\mathrm{r}}$, and how they interact with the mechanisms that drive activity-dependent changes.

\section{References}

Augustine GJ (2001) How does calcium trigger neurotransmitter release? Curr Opin Neurobiol 11:320-326.

Bean BP (2007) The action potential in mammalian central neurons. Nat Rev Neurosci 8:451-465.

Blatow M, Caputi A, Burnashev N, Monyer H, Rozov A (2003) $\mathrm{Ca}^{2+}$ buffer saturation underlies paired pulse facilitation in calbindin-D28k-containing terminals. Neuron 38:79-88.

Borst JG, Sakmann B (1996) Calcium influx and transmitter release in a fast CNS synapse. Nature 383:431-434.

Branco T, Staras K, Darcy KJ, Goda Y (2008) Local dendritic activity sets release probability at hippocampal synapses. Neuron 59:475-485.

Cao XJ, Oertel D (2010) Auditory nerve fibers excite targets through synapses that vary in convergence, strength, and short-term plasticity. J Neurophysiol 104:2308-2320.

Chanda S, Xu-Friedman MA (2010a) A low-affinity antagonist reveals saturation and desensitization in mature synapses in the auditory brain stem. J Neurophysiol 103:1915-1926.

Chanda S, Xu-Friedman MA (2010b) Neuromodulation by GABA converts a relay into a coincidence detector. J Neurophysiol 104:2063-2074.

Chanda S, Oh S, Xu-Friedman MA (2011) Calcium imaging of auditory nerve fiber terminals in the cochlear nucleus. J Neurosci Methods 195:24-29.

Cho S, Li GL, von Gersdorff H (2011) Recovery from short-term depression and facilitation is ultrafast and $\mathrm{Ca}^{2+}$ dependent at auditory hair cell synapses. J Neurosci 31:5682-5692

Clarkson C, Antunes FM, Rubio ME (2016) Conductive hearing loss has long-lasting structural and molecular effects on presynaptic and postsynaptic structures of auditory nerve synapses in the cochlear nucleus. J Neurosci 36:10214-10227.

Davis GW (2006) Homeostatic control of neural activity: from phenomenology to molecular design. Annu Rev Neurosci 29:307-323.

Delvendahl I, Kita K, Müller M (2019) Rapid and sustained homeostatic control of presynaptic exocytosis at a central synapse. Proc Natl Acad Sci USA 116:23783-23789.

Delvendahl I, Muller M (2019) Homeostatic plasticity: a presynaptic perspective. Curr Opin Neurobiol 54:155-162.

Dittman JS, Regehr WG (1998) Calcium dependence and recovery kinetics of presynaptic depression at the climbing fiber to Purkinje cell synapse. J Neurosci 18:6147-6162.

Dodge FA Jr, Rahamimoff R (1967) Cooperative action a calcium ions in transmitter release at the neuromuscular junction. J Physiol 193:419-432.

Eggermann E, Bucurenciu I, Goswami SP, Jonas P (2011) Nanodomain coupling between $\mathrm{Ca}^{2+}$ channels and sensors of exocytosis at fast mammalian synapses. Nat Rev Neurosci 13:7-21.

Fedchyshyn MJ, Wang LY (2005) Developmental transformation of the release modality at the calyx of Held synapse. J Neurosci 25:4131-4140.

Fekete A, Nakamura Y, Yang YM, Herlitze S, Mark MD, DiGregorio DA, Wang LY (2019) Underpinning heterogeneity in synaptic transmission 
by presynaptic ensembles of distinct morphological modules. Nat Commun 10:826.

Foster KA, Kreitzer AC, Regehr WG (2002) Interaction of postsynaptic receptor saturation with presynaptic mechanisms produces a reliable synapse. Neuron 36:1115-1126.

Franken TP, Roberts MT, Wei L, Golding NL, Joris PX (2015) In vivo coincidence detection in mammalian sound localization generates phase delays. Nat Neurosci 18:444-452.

Garcia-Hernandez S, Abe M, Sakimura K, Rubio ME (2017) Impaired auditory processing and altered structure of the endbulb of Held synapse in mice lacking the GluA3 subunit of AMPA receptors. Hear Res 344:284294.

Gates GA (1996) Cost-effectiveness considerations in otitis media treatment. Otolaryngol Head Neck Surg 114:525-530.

Gratz SJ, Goel P, Bruckner JJ, Hernandez RX, Khateeb K, Macleod GT, Dickman D, O'Connor-Giles KM (2019) Endogenous tagging reveals differential regulation of $\mathrm{Ca}^{2+}$ channels at single active zones during presynaptic homeostatic potentiation and depression. J Neurosci 39:2416-2429.

Grubb MS, Burrone J (2010) Activity-dependent relocation of the axon initial segment fine-tunes neuronal excitability. Nature 465:1070-1074.

Haugland RP (1996) Handbook of fluorescent probes and research chemicals. Eugene, OR: Molecular Probes.

Helmchen F, Imoto K, Sakmann B (1996) $\mathrm{Ca}^{2+}$ buffering and action potential-evoked $\mathrm{Ca}^{2+}$ signaling in dendrites of pyramidal neurons. Biophys J 70:1069-1081.

Hengen KB, Lambo ME, Van Hooser SD, Katz DB, Turrigiano GG (2013) Firing rate homeostasis in visual cortex of freely behaving rodents. Neuron 80:335-342.

Ishikawa T, Kaneko M, Shin HS, Takahashi T (2005) Presynaptic N-type and $\mathrm{P}-/ \mathrm{Q}-$ type $\mathrm{Ca}^{2+}$ channels mediating synaptic transmission at the calyx of Held of mice. J Physiol 568:199-209.

Jackman SL, Turecek J, Belinsky JE, Regehr WG (2016) The calcium sensor synaptotagmin 7 is required for synaptic facilitation. Nature 529:88-91.

Jarsky T, Tian M, Singer JH (2010) Nanodomain control of exocytosis is responsible for the signaling capability of a retinal ribbon synapse. J Neurosci 30:11885-11895.

Jenkinson DH (1957) The nature of the antagonism between calcium and magnesium ions at the neuromuscular junction. J Physiol 138:434-444.

Keck T, Keller GB, Jacobsen RI, Eysel UT, Bonhoeffer T, Hubener M (2013) Synaptic scaling and homeostatic plasticity in the mouse visual cortex in vivo. Neuron 80:327-334.

Kochubey O, Han Y, Schneggenburger R (2009) Developmental regulation of the intracellular $\mathrm{Ca}^{2+}$ sensitivity of vesicle fusion and $\mathrm{Ca}^{2+}$-secretion coupling at the rat calyx of Held. J Physiol 587:3009-3023.

Konnerth A, Llano I, Armstrong CM (1990) Synaptic currents in cerebellar Purkinje cells. Proc Natl Acad Sci USA 87:2662-2665.

Kreitzer AC, Regehr WG (2000) Modulation of transmission during trains at a cerebellar synapse. J Neurosci 20:1348-1357.

Kreitzer AC, Gee KR, Archer EA, Regehr WG (2000) Monitoring presynaptic calcium dynamics in projection fibers by in vivo loading of a novel calcium indicator. Neuron 27:25-32.

Kuenzel T, Borst JG, van der Heijden M (2011) Factors controlling the inputoutput relationship of spherical bushy cells in the gerbil cochlear nucleus. J Neurosci 31:4260-4273.

Langguth B, Kreuzer PM, Kleinjung T, De Ridder D (2013) Tinnitus: causes and clinical management. Lancet Neurol 12:920-930.

Lauer AM, Connelly CJ, Graham H, Ryugo DK (2013) Morphological characterization of bushy cells and their inputs in the laboratory mouse (Mus musculus) anteroventral cochlear nucleus. PLoS One 8:e73308.

Liberman MC (1978) Auditory-nerve response from cats raised in a lownoise chamber. J Acoust Soc Am 63:442-455.

Lin KH, Oleskevich S, Taschenberger H (2011) Presynaptic $\mathrm{Ca}^{2+}$ influx and vesicle exocytosis at the mouse endbulb of Held: a comparison of two auditory nerve terminals. J Physiol 589:4301-4320.

Lubbert M, Goral RO, Keine C, Thomas C, Guerrero-Given D, Putzke T, Satterfield R, Kamasawa N, Young SM Jr (2019) CaV2.1 alpha1 subunit expression regulates presynaptic CaV2.1 abundance and synaptic strength at a central synapse. Neuron 101:260-273.e266.

Marcotti W, Johnson SL, Rusch A, Kros CJ (2003) Sodium and calcium currents shape action potentials in immature mouse inner hair cells. J Physiol 552:743-761.
Matveev V, Bertram R, Sherman A (2011) Calcium cooperativity of exocytosis as a measure of $\mathrm{Ca}^{2+}$ channel domain overlap. Brain Res 1398:126138.

Meinrenken CJ, Borst JG, Sakmann B (2002) Calcium secretion coupling at calyx of Held governed by nonuniform channel-vesicle topography. J Neurosci 22:1648-1667.

Mintz IM, Sabatini BL, Regehr WG (1995) Calcium control of transmitter release at a cerebellar synapse. Neuron 15:675-688.

Mochida S, Few AP, Scheuer T, Catterall WA (2008) Regulation of presynaptic $\mathrm{Ca}_{\mathrm{v}} 2.1$ channels by $\mathrm{Ca}^{2+}$ sensor proteins mediates short-term synaptic plasticity. Neuron 57:210-216.

Mowery TM, Kotak VC, Sanes DH (2015) Transient hearing loss within a critical period causes persistent changes to cellular properties in adult auditory cortex. Cereb Cortex 25:2083-2094.

Müller M, Davis GW (2012) Transsynaptic control of presynaptic $\mathrm{Ca}^{2+}$ influx achieves homeostatic potentiation of neurotransmitter release. Curr Biol 22:1102-1108.

Müller M, Goutman JD, Kochubey O, Schneggenburger R (2010) Interaction between facilitation and depression at a large CNS synapse reveals mechanisms of short-term plasticity. J Neurosci 30:2007-2016.

Nakamura Y, Reva M, DiGregorio DA (2018) Variations in $\mathrm{Ca}^{2+}$ influx can alter $\mathrm{Ca}^{2+}$-chelator-based estimates of $\mathrm{Ca}^{2+}$ channel-synaptic vesicle coupling distance. J Neurosci 38:3971-3987.

Ngodup T, Goetz JA, McGuire BC, Sun W, Lauer AM, Xu-Friedman MA (2015) Activity-dependent, homeostatic regulation of neurotransmitter release from auditory nerve fibers. Proc Natl Acad Sci USA 112:64796484.

Ohana O, Sakmann B (1998) Transmitter release modulation in nerve terminals of rat neocortical pyramidal cells by intracellular calcium buffers. J Physiol 513:135-148.

Oleskevich S, Walmsley B (2002) Synaptic transmission in the auditory brainstem of normal and congenitally deaf mice. J Physiol 540:447-455.

Perkel DJ, Hestrin S, Sah P, Nicoll RA (1990) Excitatory synaptic currents in Purkinje cells. Proc Biol Sci 241:116-121.

Pfeiffer RR, Kiang NY (1965) Spike discharge patterns of spontaneous and continuously stimulated activity in the cochlear nucleus of anesthetized cats. Biophys J 5:301-316.

Popescu MV, Polley DB (2010) Monaural deprivation disrupts development of binaural selectivity in auditory midbrain and cortex. Neuron 65:718731.

Qi Y, Yu S, Du Z, Qu T, He L, Xiong W, Wei W, Liu K, Gong S (2019) Longterm conductive auditory deprivation during early development causes irreversible hearing impairment and cochlear synaptic disruption. Neuroscience 406:345-355.

Regehr WG, Atluri PP (1995) Calcium transients in cerebellar granule cell presynaptic terminals. Biophys J 68:2156-2170.

Reyes A, Lujan R, Rozov A, Burnashev N, Somogyi P, Sakmann B (1998) Target-cell-specific facilitation and depression in neocortical circuits. Nat Neurosci 1:279-285.

Ryugo DK, Fekete DM (1982) Morphology of primary axosomatic endings in the anteroventral cochlear nucleus of the cat: a study of the endbulbs of Held. J Comp Neurol 210:239-257.

Sabatini BL, Regehr WG (1995) Detecting changes in calcium influx which contribute to synaptic modulation in mammalian brain slice. Neuropharmacology 34:1453-1467.

Sabatini BL, Regehr WG (1997) Control of neurotransmitter release by presynaptic waveform at the granule cell to Purkinje cell synapse. J Neurosci 17:3425-3435.

Schmidt H, Brachtendorf S, Arendt O, Hallermann S, Ishiyama S, Bornschein G, Gall D, Schiffmann SN, Heckmann M, Eilers J (2013) Nanodomain coupling at an excitatory cortical synapse. Curr Biol 23:244-249.

Schneggenburger R, Han Y, Kochubey O (2012) $\mathrm{Ca}^{2+}$ channels and transmitter release at the active zone. Cell Calcium 52:199-207.

Sharp AA, O'Neil MB, Abbott LF, Marder E (1993) Dynamic clamp: computer-generated conductances in real neurons. J Neurophysiol 69:992995.

Skoe E, Krizman J, Anderson S, Kraus N (2015) Stability and plasticity of auditory brainstem function across the lifespan. Cereb Cortex 25:14151426.

Song P, Yang Y, Barnes-Davies M, Bhattacharjee A, Hamann M, Forsythe ID, Oliver DL, Kaczmarek LK (2005) Acoustic environment determines 
phosphorylation state of the Kv3.1 potassium channel in auditory neurons. Nat Neurosci 8:1335-1342.

Sudhof TC (2012) Calcium control of neurotransmitter release. Cold Spring Harb Perspect Biol 4:a011353.

Sun W, Lu J, Stolzberg D, Gray L, Deng A, Lobarinas E, Salvi RJ (2009) Salicylate increases the gain of the central auditory system. Neuroscience 159:325-334.

Taschenberger H, Leao RM, Rowland KC, Spirou GA, von Gersdorff H (2002) Optimizing synaptic architecture and efficiency for high-frequency transmission. Neuron 36:1127-1143.

Thanawala MS, Regehr WG (2013) Presynaptic calcium influx controls neurotransmitter release in part by regulating the effective size of the readily releasable pool. J Neurosci 33:4625-4633.

Tsien RY (1980) New calcium indicators and buffers with high selectivity against magnesium and protons: design, synthesis, and properties of prototype structures. Biochemistry 19:2396-2404.

Turrigiano GG, Leslie KR, Desai NS, Rutherford LC, Nelson SB (1998) Activity-dependent scaling of quantal amplitude in neocortical neurons. Nature 391:892-896.

Wang LY, Neher E, Taschenberger H (2008) Synaptic vesicles in mature calyx of Held synapses sense higher nanodomain calcium concentrations during action potential-evoked glutamate release. J Neurosci 28:1445014458.

Whitton JP, Polley DB (2011) Evaluating the perceptual and pathophysiological consequences of auditory deprivation in early postnatal life: a comparison of basic and clinical studies. J Assoc Res Otolaryngol $12: 535-547$.
Xu-Friedman MA, Harris KM, Regehr WG (2001) Three-dimensional comparison of ultrastructural characteristics at depressing and facilitating synapses onto cerebellar Purkinje cells. J Neurosci 21:6666-6672.

Yang H, Xu-Friedman MA (2008) Relative roles of different mechanisms of depression at the mouse endbulb of Held. J Neurophysiol 99:2510-2521.

Yang H, Xu-Friedman MA (2009) Impact of synaptic depression on spike timing at the endbulb of Held. J Neurophysiol 102:16991710

Yang H, Xu-Friedman MA (2010) Developmental mechanisms for suppressing the effects of delayed release at the endbulb of Held. J Neurosci 30:11466-11475.

Yang H, Xu-Friedman MA (2013) Stochastic properties of neurotransmitter release expand the dynamic range of synapses. J Neurosci 33:1440614416.

Yang Y, Xu-Friedman MA (2015) Different pools of glutamate receptors mediate sensitivity to ambient glutamate in the cochlear nucleus. J Neurophysiol 113:3634-3645.

Yang Y, Adowski T, Ramamurthy B, Neef A, Xu-Friedman MA (2015) Highspeed dynamic-clamp interface. J Neurophysiol 113:2713-2720.

Zhao C, Dreosti E, Lagnado L (2011) Homeostatic synaptic plasticity through changes in presynaptic calcium influx. J Neurosci 31:7492-7496.

Zhou F, Shefer A, Kong Y, Nuorti JP (2008) Trends in acute otitis mediarelated health care utilization by privately insured young children in the United States, 1997-2004. Pediatrics 121:253-260.

Zhuang X, Sun W, Xu-Friedman MA (2017) Changes in properties of auditory nerve synapses following conductive hearing loss. J Neurosci $37: 323-332$. 